\title{
Wind pressures on large roofs of low buildings and wind codes and standards Hatem Alrawashdeh*, Ted Stathopoulos
}

Department of Building, Civil and Environmental Engineering, Concordia University, Montreal, Quebec, Canada

*Corresponding Author: h_alraw@encs.concordia.ca

\begin{abstract}
:
Current wind codes and standards have load provisions dealing with low buildings of common configurations. Large buildings, say $100 \mathrm{~m}$ long, had not been considered when these provisions were established. As a result, the interaction between wind and buildings of such geometries should be investigated for the assessment of current wind provisions in terms of their applicability to such configurations. The present wind tunnel study examines nine large low-rise buildings $5,7.5$ and $10 \mathrm{~m}$ high for several wind directions ranging from $0^{\circ}$ to $90^{\circ}$ at increments of $15^{\circ}$. The buildings have square plans with full-scale horizontal dimensions ranging from 60 to $180 \mathrm{~m}$. Results show that building plan sizes have significant effects on the generated wind loads on building roofs. Also, application of current provisions on building geometries of large roofs and low height may lead to considerably conservative and uneconomic design. An exception for very large low buildings, as far as the determination of the sizes of roof edge and corner zones is concerned, has been recommended to rectify the deficiency of wind code and standard provisions for these building geometries.
\end{abstract}

\section{Introduction}

There are many issues to be addressed by researchers and engineers in the wind engineering field to provide guidelines for secure and economic design. Over the past five decades a quantum leap on wind pressures of low-rise buildings has been realized through a series of comprehensive studies. This started by pioneering comprehensive research in the mid-seventies (Davenport et al. 1977, 1978) and continued for several years. This research investigated various geometries of low-rise buildings by means of wind 
tunnel tests, where the importance of the boundary layer flow and the effect of turbulence were included. Also, the studies introduced several techniques to codify the results of the wind-tunnel tests such as the pneumatic-averaging method (Surry and Stathopoulos, 1978) to estimate instantaneous areaaveraged pressure coefficients. The results of this pioneering research have formed the backbone of the NBCC and ASCE 7 wind provisions (wind loads for components and cladding and MWFRS-envelope method).

A number of wind-engineering investigators have also presented wind measurement results in the form of wind loads and reviews for low-rise buildings, e.g., Stathopoulos (1984-B); Holmes (1993); Krishna (1995); Kasperski (1996); Stathopoulos et al (1996); Uematsu and Isyumov (1999); Ho et al (2005); and St. Pierre et al (2005).

Over the past years the wind load on interior areas of flat roofs of low-rise buildings has been intensely investigated by wind tunnel and full-scale experiments. Gerhardt and Kramer (1992) studied the influence of relative building height (eave height/width, H/B) on the pressure distribution over flat roofs of models with constant height and varying height to width ratios (0.04 to 0.4$)$. Accordingly, Gerhardt and Kramer observed that "The relative building height for buildings with $H / B \geq 0.1$ influences the roof pressure distribution strongly". Extensive pressure data have been collected on a scaled model of the Texas Tech University (TTU) experimental building in a wind-tunnel simulated atmospheric boundary layer (Cochran and Cermak, 1992). Milford et al (1992) presented a comparison between fullscale and wind tunnel results obtained at the Division of Building Technology for the Jan Smuts Airport hangar. Lin et al (1995) studied roof pressures of low-rise buildings for a series of models of varying height and plan size in two different flows. The study investigated the roof pressure distribution under the corner vortices and its variation with wind angle, building dimensions and incident flow characteristics. Lin and Surry (1998) examined the effect of spatial averaging of roof pressures on peak loads over various tributary areas near the corner of flat-top low-rise buildings. 
Morrison and Kopp (2007) have extended the work done by Ho et al (2005) and have compared mean and RMS pressure coefficients normalized by roof height for different heights and plan dimensions. The study found that the definition of the edge zone in ASCE 7 requiring that the edge zone be a minimum of $4 \%$ of the smallest building plan dimension affects buildings with very large plan dimensions when compared to the roof height. However, the study has found that there is very little change in the wind loading on the roofs of buildings based on plan dimensions and seems to scale primarily with the roof height. Consequently, the requirement that the edge zone be at least $4 \%$ of the smallest building plan dimension may artificially increase the size of the edge zone, although no increase in wind loading on the roof really exists.

Previous experiments mentioned above in the literature review have been performed on model simple shapes of low-rise buildings with common, relatively small, dimensions. However, low-rise buildings have limitless possibilities of geometries that include different heights, roof slopes and horizontal plan dimensions. With the urban and industrial activity growth, low-rise buildings are used for commercial and industrial purposes like malls and shopping centres with large flat or nearly flat roofs. Figure I presents an example of a commercial building, the Mushroom warehouse, located in Southeastern Pennsylvania, United States. This barn is supported by a truss system of I:I2 pitch and has plan dimensions of $61 \mathrm{~m}$ by $152 \mathrm{~m}$ and an eave height of $5 \mathrm{~m}$. Such structures may be indeed penalized by applying roof zone provisions currently in the North American wind codes and standards. Furthermore, a similar situation exists in retrofitting or refurbishing buildings. For example, extension of an existing building would modify the size of the roof zones (corner, edge and interior) even for the old portion of the building. The question then remains whether the requirements of the wind codes and standards are really justified when building dimensions are increased.

The current wind loading provisions of ASCE 7-10 (USA) and NBCC 2010 (Canada) were produced by testing regular-shaped models with common relatively small dimensions. As a result, the 
design criterion $4 \%$ of the least horizontal dimension $(0.04 \mathrm{Ds}$ ) could become extremely expensive for flat roofs of large low-rise buildings. Therefore, the aim of this paper is to provide the necessary information about the characteristics of the fluctuating wind pressures on edges and corners of roofs of low-rise buildings with very large dimensions compared with their heights found through a wind tunnel experimental study; also, to examine the wind provisions given by North American codes and standards in order to assess their applicability to very large buildings. Suggestions will then be made for these codes and standards, based on the experimental results of this wind tunnel study.

\section{Wind loads on roof cladding of low-rise buildings}

The definition of low-rise buildings and the roof angle $(\alpha)$ ranges are somewhat different in various national wind standards and codes of practice. The definitions of flat-roofed low-rise buildings provided in the American Society of Civil Engineers Standard (ASCE 7, 20I0), the National Building Code of Canada (NBCC, 2010), the European Standard (EN 199I-I-4:2005) and the Australian/New Zealand Standard (AS-NZS II 70-2, 20II) are presented in Figure 2. For the range of these heights and roof angles wind codes/standards provide the design wind pressures for the components and cladding of roofs, walls and frames of low-rise buildings regardless of the building plan dimensions.

The methodologies used by the four codes/standards mentioned above, for calculation of building pressures are summarised in Table I. Clearly the approaches in the various codes and standards are different. Even though the basic wind speed $(\mathrm{V})$ in all of the wind codes/standards is defined at $10 \mathrm{~m}$ above ground surface in open country exposure, the averaging time and wind velocity profiles are different. For instance, the basic wind speed used in NBCC-20I0 has a longer averaging time (I-hr) compared with the 3-sec averaging time used in ASCE 7-10 and the wind velocity profiles are fitted by either the power law or logarithmic law, as indicated. Therefore, since the gust factors for computing pressure coefficients used in ASCE 7-10 will be lower than those in NBCC-2010, the current values of 
the gust pressure coefficients used in the ASCE7-10 will be lower than those in NBCC-20I0 in order to yield comparable design wind pressures.

The wind pressure values obtained by Davenport et al. $(1977,1978)$ at the University of Western Ontario; Holmes and Best (1978) at the James Cook University of North Queensland; and Stathopoulos (1981), Stathopoulos and Zhu (1988), Stathopoulos and Luchian (1990, 1992), and Stathopoulos and Saathoff (199I) at Concordia University were refined to reflect results of full-scale tests obtained by Marshall (1977) at the National Bureau of Standards; and Eaton and Mayne (1975) at the Building Research Station, England. Then, these values were used to generate current wind pressure provisions in ASCE7-IO (components and cladding) for enclosed or partially enclosed low-rise buildings with flat roof, hip roof and gable roof.

As already mentioned, ASCE 7-10 and NBCC 2010 give the external peak pressure coefficients on building cladding directly as $\mathrm{GC}_{g}$ and $\mathrm{C}_{\mathrm{p}} \mathrm{C}_{\mathrm{g}}$, respectively. Thus, the design pressure coefficients are given directly for the loading zones in simple graphs versus the tributary area. Figure 3 presents ASCE 710 and NBCC 2010 roof zones and the external peak pressure coefficients, $C_{p} C_{g}$, on edge, corner and interior zones of flat roof buildings. As reference for comparison, mean hourly velocity pressure at mean roof height is used for the pressure coefficients in this figure.

There is numerical variation between the ASCE 7-10 and NBCC 2010 values, such that the values recommended by ASCE 7-I0 are somewhat higher than those recommended by NBCC 2010 for some zones. This disparity is partly due to the directionality factor $K_{d}=0.85$ which applies to ASCE 7-10 but not to NBCC 2010, since the latter has already incorporated some of this this effect in the $C_{p} C_{g}$ values. Therefore, to make the code pressure coefficients comparable, the values of ASCE 7-I0 in Figure 3 have been multiplied by 0.85 . ASCE $7-10$ and NBCC 2010 provide also positive pressure coefficients for all zones as functions of tributary area. 


\section{I Zonal systems for flat roofs in current wind codes and standards}

Wind experiments conducted on different roof configurations have expressed the wind loading on the roof typically (but not always) within boundaries of three zones. Pressure coefficients range from the lowest values on interior areas of the roof, to higher values around the perimeter of the roof, to the highest values on the roof corners. Standards and codes of practice divide the entire flat roof of the building into at least three zones, namely: corner, edge and interior - see Figure 3.

NBCC 2010 and ASCE 7-10 recommend to use square shaped corner zone and its size depends on the height and the least horizontal dimension of the building with ratios built up to provide the suitable size for various low-rise building geometries. The current ASCE 7-I0 and NBCC 2010 define the edge zone width $(Z)$ as follows: "End- zone width $Z$ is the lesser of $10 \%$ of the least horizontal dimension and $40 \%$ of the height, $h$, but not less than $4 \%$ of the least horizontal dimension or Im". (NBCC 20I0). These conditions are shown graphically at the lower part of Figure 3 for buildings with three different H/Ds ranges denoted by I, II and III.

The roof patterns and the guidelines to create the roof zones adopted by ASCE 7-10 and NBCC 7-10 are largely based on research conducted in the late 1970s by Stathopoulos (1979). This comprehensive study aimed directly at the codification and zone description suitable for design pressure coefficients to be used for wind loading. Roof zones were generated by examining roof pressures from several studies with different building heights, plan dimensions, wind simulation conditions and geometric scales. Table 2 summarizes all examined experimental studies along with their sources. Generally, the investigation included every combination of different near-flat roofs with angles between 0 and 7 degrees; and different plan dimensions. Also, experiments carried out at different scales (full scale and wind tunnel scale) with different terrain exposures were considered. Wind tunnel experiments were from different boundary layer wind tunnel laboratories, so a fair amount of variability of the results was expected. 
A pattern of zones on flat roofs was created based on the pressure coefficients measured on the roof surface by investigating the actual mean and peak pressure distribution over the roofs of the buildings. For normal wind direction two patterns of pressure distribution have been observed depending on the building plan size; see Figure 4. Figure 4(a) represents the general simplified trace of pressure distribution over relatively small roofs - for this group of buildings the pressure distribution collapses slowly; moreover, the reattachment (if any) occurs further away from the leading edge. Figure 4(b) represents the general trend of pressure distribution over relatively large roofs. For this case, the pressure distribution collapses rapidly until the point of first reattachment and thereafter the flow is retreated close to the surface and runs away smoothly. Based on the observed pressure distribution patterns, a methodology of two forms was derived to define the sizes of the roof zones: first, the edge zone size was defined as the distance required for the maximum negative peak or mean pressure coefficient at the leading edge to reach to $70 \%$ of its value - see Figure 4(a); second, the edge zone size was defined as the distance from the leading edge to the point where the flow is being reattached - see Figure 4(b).

The edge/corner zone sizes created according to this methodology are denoted by " $Z$ " and shown in Table 2 for all different cases. The ratios of edge zone size to building height $(\mathrm{Z} / \mathrm{H})$ and edge zone size to minimum horizontal plan dimension $(\mathrm{Z} / \mathrm{B})$ have also been provided. These ratios $(\mathrm{Z} / \mathrm{H}$ and Z/B) were enveloped and transformed to be the design parameters of the roof zoning guidelines as minimum of $0.4 \mathrm{H}$ and $0.1 \mathrm{Ds}$. In addition, a minimum size of $0.04 \mathrm{Ds}$ or $\mathrm{Im}$ was introduced to accommodate all cases. Indeed, the parameter $0.04 \mathrm{Ds}$ was found to be the least among all Z/B ratios examined. Also, the least edge zone size among all examined buildings was found equal to $\mathrm{Im}$, so this was considered the lowest possible edge zone size.

The size of the edge zone may be small or large depending on the building configuration. So the reference should be made to situations where each parameter of ASCE 7-10 and NBCC 2010 (0.IDs, 
$0.4 \mathrm{H}$ or $0.04 \mathrm{Ds}$ ) could dominate the edge zone width. For example, roofs of buildings of very large horizontal dimensions compared with their heights may be designed according to the design criterion (0.04Ds) - see lower part of Figure 3. As can be noticed, not too many buildings of these geometries have been considered in Table 2 . Hence, the present study is really warranted.

\section{Experimental work}

All experiments for the present study have been carried out in the boundary layer wind tunnel at the Building Aerodynamics Laboratory, Concordia University; see Figure 5. The blow-down tunnel is of the open-circuit design with working section of $1.80 \mathrm{~m}$ in width, $12.2 \mathrm{~m}$ in length and has adjustable roof height in the range of $1.40 \mathrm{~m}$ to $1.80 \mathrm{~m}$ to provide the necessary height for different exposures. Also, the tunnel is provided with a turntable of $1.60 \mathrm{~m}$ diameter at test section, which allows testing models for different wind directions. The wind speed at the test section ranges between $3 \mathrm{~m} / \mathrm{s}$ and $14 \mathrm{~m} / \mathrm{s}$. A typical I:400 to I:500 length scale $\left(\lambda_{l}\right)$ was recommended by Stathopoulos (1984-A). This can be larger for testing low-rise buildings; a small relaxation of scale (up to a factor of 2 ) is permissible for both local and area loads (Stathopoulos and Surry, 1983). A thick carpet on the floor generates the required velocity and turbulence profiles of open-country exposure. Detailed information about the wind tunnel including construction details and its simulations are provided by Stathopoulos (1984-A).

\section{I Atmospheric boundary layer and terrain exposure}

An open-country exposure has been simulated in the wind tunnel for this study. Figure 6 shows the approach flow profiles of mean wind velocity and turbulence intensity at the test section measured using a 4-hole Cobra probe (TFI). The wind velocity at free stream was $11.0 \mathrm{~m} / \mathrm{s}$ at gradient height of $Z_{G}=60 \mathrm{~cm}$. The wind characteristics at the test section are described by the power-law model and 
according to that the variation of mean wind speed with height was generated with power law index $(\alpha)$ of 0.15 .

\subsection{Building models}

Wind tunnel tests have been conducted for nine low building models with flat square roofs with full-scale equivalent dimensions ranging from $60 \mathrm{~m}$ to $180 \mathrm{~m}$. The basic model of the tested buildings has full-scale equivalent plan dimensions of $60 \mathrm{~m}$; it is made of Plexi-glass and is equipped with 127 roof pressure taps. The basic model has been used in simulation of other buildings of large roofs that were taken into account in this study i.e. buildings of plan dimensions of $120 \mathrm{~m}$ and I $80 \mathrm{~m}$. This has been done by combining the basic model (equipped pressure taps model) with a matrix of similar geometry wooden blocks, as shown in Figure 7. The measurement results of large roofs (width $=120 \mathrm{~m}$ and $180 \mathrm{~m}$ ) have been collected independently by placing the basic model at different locations, for which the pressure coefficients on the entire roof of the building have been scanned for a particular wind direction, whereas the roof pressure coefficients of the basic model (width $=60 \mathrm{~m}$ ) have been measured simultaneously.

All model buildings were tested at equivalent full-scale heights of $5.0,7.5$ and $10.0 \mathrm{~m}$, by sliding the models downwards in a precise tightly fit slot in the turntable. Table 3 summarizes all nine configurations of low-rise buildings tested in this study ( $\mathrm{BI}$ to $\mathrm{B9}$ ).

\subsection{Modeling requirements}

In order to maintain aerodynamic pressure coefficients on cladding of sharp-edged buildings measured by boundary layer wind tunnel experiments consistent with the pressure coefficients on surface of full-scale structure, length, time and velocity scales used in the wind tunnel must be consistent with respective atmospheric conditions.

(1) $\quad\left(\frac{\lambda_{l}}{\lambda_{V} \lambda_{T}}\right)_{W T}=\left(\frac{\lambda_{l}}{\lambda_{V} \lambda_{T}}\right)_{F S}$ 
where $\lambda_{l}=$ length scale; $\lambda_{V}=$ velocity scale and $\lambda_{T}=$ time scale (whose reciprocal is the frequency scale, $\lambda_{f}$ ). The subscripts FS and WT refer respectively to full scale building and wind tunnel model.

Furthermore, another issue related to wind tunnel simulation requirements is similarity of Reynolds number. In case of sharp-edged structures immersed in boundary layer flow, the similarity of Reynolds number is less significant. "Sharp corners tend to cause immediate flow separation, independently of the Reynolds number of the flow. For this reason it is generally assumed that if the flow is adequately simulated, pressures on rectangular and other sharp cornered are adequately reproduced in the wind tunnel" (Simiu and Scanlan, 1996). Consequently, the similarity of model and full-scale Reynolds number is not a serious constraint and can be relaxed; this applies well to bodies with sharp edges in turbulent flow.

So far, wind tunnel testing for buildings and other structures (ASCE, 20I0) sets criteria to accurately simulate the wind tunnel experimental studies. This standard provides minimum requirements for Reynolds number of the model simulation in wind tunnel to neglect the variation in pressure distributions on account of the expected distortion in the flow; accordingly, model Reynolds number shall be more than II,000 ( $R_{e b}=\frac{V_{H} L_{b}}{v} \geq 11,000$, where $L_{b}$ : characteristic length scale of a model). Also, the European standard (EN 199I-I-4:2005) defines Reynolds number of the model based on the width of the structure and the mean wind velocity at building height (Geurts and Bentum, 2007). The minimum $R_{e b}$ criteria are thus satisfied in this case.

\subsection{Pressure measurements}

The pressure measurements on surface of the models were accomplished by connecting the pressure taps that are distributed on the roof of the model to a system of miniature pressure scanners made up of Scanivalve pneumatic modules (ZOC33/64Px), each capable of handling 64 channels 
(pressure taps), and a digital service module (DSM 3400). The pressure scanners are calibrated to scan the pressure signals at frequency of $300 \mathrm{~Hz}$ (300 samples per second) for a total period of 27 seconds on wind-tunnel scale. A geometric scale of $1: 400$ has been used for all experiments of this wind tunnel study. The velocity scale of the wind tunnel is about $1: 3$ and therefore the time scale is approximately I:I33.

The instantaneous surface pressures over the entire roof have been measured in the test section of the wind tunnel for wind directions of quarter cycle $\left(0^{\circ}\right.$ to $\left.90^{\circ}\right)$ at increments of $15^{\circ}$. The measured pressures have been normalized by the mean dynamic pressure measured at reference height to express them as non-dimensional pressure coefficients, $C_{P_{1}}(t)$ defined as

$$
\mathrm{C}_{\mathrm{Pi}}(\mathrm{t})=\frac{\mathrm{P}_{\mathrm{i}}(\mathrm{t})-\mathrm{P}_{\mathrm{s}}}{\bar{q}_{\mathrm{z}}}, \quad \bar{q}_{\mathrm{z}}=\frac{1}{2} \rho \bar{V}_{H}^{2}
$$

in which $\mathrm{P}_{\mathrm{i}}(\mathrm{t})$ is the wind pressure at pressure tap $(\mathrm{i}), \mathrm{P}_{\mathrm{s}}$ is the static pressure at reference location, $\bar{q}_{z}$ is mean value of the dynamic velocity pressure at height $Z_{\text {ref, }} \rho$ is the density of the air and $\bar{V}_{H}$ is mean value of the wind velocity at roof height, $H$.

The instantaneous area-averaged wind pressures over the effective area are calculated for each wind direction by integrating the instantaneous local wind pressures over the area, i.e.

$$
C_{p, A}(t)=\frac{1}{\sum_{i=1}^{n} A_{i}} \sum_{i=1}^{n}\left(C_{p i}(t) A_{i}\right)
$$

in which $C_{p, A}(t)$ is the area-averaged wind pressure coefficients at instant $(\mathrm{t}), \mathrm{A}_{\mathrm{i}}$ is the contributing area to the $i^{\text {th }}$ pressure tap and $n$ is number of pressure taps in the specified area $A_{i}$.

Peak pressure coefficients in the time history records are determined based on analysis methods used in many previous studies, e.g. Elsharawy et al. (20l4). Finally, the negative sign of the wind pressure coefficients indicates that the wind pressure is acting away from the surface (suction pressure). 


\subsection{Uncertainty of the measurements}

The uncertainty and variability of the measurements are examined in order to look at the reliability of the results. This was carried out by a comparative process, which consists of two parts: The first part compares wind tunnels peak and mean pressure coefficients for central line of pressure taps for $0^{\circ}$ wind direction from the original tests and similar repeated tests. Figure 8 shows the pressure coefficients of this study and of the repeated tests for building configurations B4 and B7. As shown in Figure 8, a good agreement is achieved between the original measurements and the repeatability results for both mean and peak pressure coefficients.

The second part compares the measurements of this study with another set of wind tunnel data obtained by Stathopoulos and Dumitrescu-Brulotte (1989). Figure 9 shows the mean and peak lines of pressure coefficients along the centre of the roof for wind direction perpendicular to the windward edge from Stathopoulos and Dumitrescu-Brulotte (1989) for building of dimensions (6IX6IXI2m), and those from this study for building model $\mathrm{BI}(60 \times 60 \times 10 \mathrm{~m})$. Both studies were carried out on wind tunnel open country exposure with same power low exponent values. The values of the pressure coefficients shown in this figure are in extremely good agreement, as expected since the $A B L$ simulation and model configuration are almost the same.

Therefore, the good agreement of the original test results with the repeated test data and the results of another wind tunnel study is quite encouraging for further application of these wind tunnel results.

\section{Experimental results and discussion}

Wind-induced pressures on the roofs of isolated buildings depend on the roof geometry and dimensions, building height and the characteristics of the approaching wind. Roof dimensions affect the 
external flow patterns, such as flow reattachments on roofs with large dimensions. This implies lower pressure magnitudes on most parts of the roof in comparison with smaller roofs.

Figure 10 represents the instantaneous wind pressures over the centre of a large flat roof for wind direction normal to the leading edge for a total period of 27 seconds (3600 seconds in full-scale). This figure was obtained by superposition of the measured pressure-time history records at different locations on the roof centre. As depicted in the figure, the wind pressure fluctuations on the windward area are much higher than the fluctuations on the leeward area (in the range of four to five), as evidenced by the time history records attached to the figure, at the windward edge and middle of the roof. Consequently, the statistical correlation between pressures separated by large distances will be very small.

\section{I Effect of building height}

The effect of building height on wind loads acting on large building roofs has been examined by comparing the measured wind pressure coefficients on roofs of different configurations. The results show that the lower buildings show the steeper pressure lines throughout the separation zones. The values of negative peak pressure coefficients throughout the separation regions increase with increasing the building height. However, the distance to the point the flow gets to reattach to the roof is little affected by the height of the building. For instance, the roof pressure gradients of buildings of width $B=60 \mathrm{~m}$ occur to $\mathrm{Y} / \mathrm{L}<0.5$ for the building heights of $5 \mathrm{~m}, 7.5 \mathrm{~m}$ and $10 \mathrm{~m}$.

\subsection{Effect of building plan size}

For certain roof height, three buildings of different plan dimensions are chosen for comparison to investigate the effect of the building plan size on the generated roof wind pressures. The chosen buildings are $\mathrm{BI}, \mathrm{B} 2$ and $\mathrm{B} 3$. Figures $\mathrm{II}$ and $\mathrm{I} 2$ show the negative peak and mean pressure coefficients 
trace along lines of pressure taps. The lines were selected at mid-span for wind direction $0^{\circ}$ and near the concurrent roof edge for $45^{\circ}$ wind direction.

As can be seen in Figure $\mathrm{II}$, the highest suction near the windward edge decreases with increasing distance from the windward edge. Additionally, Figure II shows that for normal wind direction the value of the reattachment length increases by a factor of 1.5 for buildings of very large roofs (i.e. B3) as compared to that for other buildings. In terms of relative distances, the position of the reattachment point for buildings of smaller dimensions $(B=60 \mathrm{~m})$ is at around $Y / L=0.6$, whereas for buildings of larger dimensions $(B=\mid 20 \mathrm{~m}$ and $B=180 \mathrm{~m})$ reattachment points are at around $Y / L=0.3$. This shows that the pressure coefficients of relatively low values exist throughout the majority of the roof area of building with large dimensions. On the other hand, for buildings with smaller plan dimensions, most of the roof area is engulfed under the separated flow, and therefore, pressures of relatively high values exist over the majority of the roof area.

The results for $45^{\circ}$ wind direction are presented in Figure 12. The lines were selected near the concurrent roof edges in order to cross the path of the conical vortices in these zones. The location of pressure lines is shown in Figure 12. The traces of the mean and negative peak pressure coefficients shown are clearly affected by the two Delta wing vortices developed along each concurrent roof edge. Note that the buildings of width $B=180 \mathrm{~m}$ show a somewhat different behaviour particularly at $\mathrm{Y} / \mathrm{L}$ near 0.4. This is to say that in general, the wind flow reattachment pattern is somewhat different for very large buildings.

\subsection{Size of corner and edge zones}

The same methodology implemented for the ASCE 7-10 and NBCC 2010 has been applied to this study to create the roof zones of the tested models by using the patterns shown in Figure 4. Therefore, the width $Z$ of the edge/corner zone has been established for all tested roofs and wind directions considered in this study. Roof zone sizes of the tested buildings for all wind directions are 
summarized in Table 4. Roof zones for wind directions only from $0^{\circ}$ to $45^{\circ}$ are presented because of the symmetric shape of the square building plans. The envelope values for edge/corner zone width occur mainly at normal wind directions; thus for oblique wind directions, the pressure distributions are steeper than in the case of normal wind direction. This makes getting the $70 \%$ of $C_{p, \text { worst }}$ in shorter distances for oblique wind direction.

For buildings with height $7.5 \mathrm{~m}$ and less the values of roof pressures are leading edge distanceindependent, whereas the effect of the building height seems to be major. This is clear from the edge and the corner zones in Table 4, which were created based on the roof pressure distributions. Thus, for buildings with height $7.5 \mathrm{~m}$ and $5 \mathrm{~m}$ the sizes of the edge and corner zones are, respectively, found to be about $5.3 \mathrm{~m}$ and $3.4 \mathrm{~m}$ regardless of the building plan dimensions. The situation is completely different for higher buildings where the variation of roof pressures and then the roof zones are affected by the building plan dimensions. The envelope values of edge and corner zones are applicable to code/standard comparisons and codification.

\subsection{Area-averaged pressure coefficients}

In addition to local pressure coefficients, area-averaged pressure coefficients are very important, since the wind loads acting on roof members are generally reduced due to area-averaging of wind pressures. Also, since the design wind loads of the current wind codes and standards are specified as a function of the loading area (tributary area), the most critical area-averaged pressure coefficients are important in order to examine the suitability of the current wind load provisions for very large low buildings. For purpose of calculating the area-averaged wind pressure coefficients in this study, eight square tributary areas of different sizes ranging between $2.4 \mathrm{~m}^{2}$ and $827 \mathrm{~m}^{2}$ were selected at the leading corner of the building roof containing one pressure tap and 48 pressure taps, respectively. This multiple square tributary area with multiple taps technique has been used in many previous studies, e.g. Hosoya et al. (1999) and Peterka et al. (1998). 
Figure 13 presents the most critical negative peak area-averaged pressure coefficients for the corner zones recorded for all wind directions for each tested model. These coefficients are provided as a function of tributary area, consistently with the current North American standards and codes. Figure 13 shows that the area-averaged pressure coefficients decrease in value over the tributary areas with significant reduction from the local peak negative pressure coefficient. Greater reductions are observed at larger tributary areas. For tributary areas larger than $2.5 \mathrm{~m}^{2}$, the area-averaged pressure coefficients approximately decrease linearly with the tributary area. Moreover, Figure I 3 indicates that the values of the most critical negative peak pressure coefficients (local and area averaged loads) measured over the leading corners of the roofs seem to be little affected by the building plan dimensions for the three heights considered in this study. Generally, the area-averaged pressure coefficients increase with height.

\section{Comparison of the experimental results with the ASCE 7-10 and NBCC 2010}

\section{Provisions}

It is important to compare the wind tunnel measurement results with the current code and standard provisions to stand on their adequacy in predicting suitable design wind loads for corner and edge roof zones. The key area of the comparison will be the provisions regarding roof zonal systems and design wind pressure coefficients with their appropriateness for large buildings. The comparison will address the ASCE 7-I0 and NBCC 2010 provisions. It should be noted that the pressure coefficients of ASCE 7-10 that will be incorporated into the comparisons with the wind tunnel results and the corresponding NBCC 2010 values have been multiplied by the reduction factor of 0.85 to account for directionality; further information concerning this factor is provided by Davenport (1983).

\section{I Recommended edge and corner zones}


Comparison of the roof zone sizes of the experimental results with those created by the current guidelines of the wind codes/standards considered in this study are presented in Table 5. Roof zones of ASCE 7-I0 and NBCC 2010 for most tested roofs in this study are created by the design criterion $4 \%$ of the least horizontal dimension (0.04Ds).

Table 5 shows that for buildings with low height and large roofs ( $B \geq 120 \mathrm{~m}$ and $H \leq 7.5 \mathrm{~m})$, the sizes of the edge and corner zones of this study are considerably smaller than the sizes created by ASCE 7-I0 (NBCC 2010) guidelines. The disagreements between the experimental results and the respective code values are due to the zoning parameter $4 \%$ of the least horizontal dimension (0.04Ds). For instance, the edge zone size of ASCE 7-10 (NBCC 2010) for building (B9) is found to be twice as large as the actual (experimental) size. On the contrary, for relatively high and large roof buildings (B3), the sizes of the edge and corner zones created by this investigation are comparable to the current ASCE 7-10 (NBCC 2010) guidelines.

Moreover, the current roof zones of ASCE 7-I0 (NBCC 20I0) and experimental roof pressure distributions have been investigated together. For illustration purposes, the contour distribution of most critical peak pressure coefficients over the perimeters of roofs of the models B7: $60 \times 60 \times 5 \mathrm{~m}$, B8: 120X120X5 m and B9: 180X180X5 m are drawn in Figure 14 with roof zones of current provisions of ASCE 7-I0 and NBCC 20I0. Since the roof models are square, these contours of pressure coefficients take advantage of the symmetry of the roof models, thus the contours on a quarter of the roof reflect the pressure distribution on the entire roof perimeter. The summary of this investigation is presented in Table 6, in which the minimum values (in absolute sense) of most critical pressure coefficients captured by each corner and edge zone of current provisions are provided. These are the values at the boundaries with the roof interior zone.

Table 6 shows that for buildings with large roofs $(B \geq 120 \mathrm{~m})$ and relatively low heights $(H \leq 7.5$ m) the current provisions of ASCE 7-10 and NBCC 2010 have a tendency to provide very conservative 
corner and edge zones of unjustified size increases - with attention to values of the design local pressure coefficient of the interior zones recommended by ASCE 7-10 and NBCC 2010 for local areas (Figure 3)

- it is observed that very low values of pressure coefficients, even lower than the code design local pressure of interior zones, are held by edge and corner zones of these buildings ( $B \geq 20 \mathrm{~m}$ and $\mathrm{H} \leq 7.5$ m). For instance, for building model (B7: $60 \times 60 \times 5 \mathrm{~m})$ the current code/standard edge and corner zones capture all peak pressure coefficients higher (in absolute sense) than -2.5 and -2.0 , respectively; whereas the code corner and edge zones of the building model (B9: $180 \times 180 \times 5 \mathrm{~m}$ ) capture the local peak pressure coefficients to a very conservative degree; thus, $\mathrm{CpCg}$ values much higher than -I.3.

\subsection{Recommended roof pressures}

The most critical area-averaged peak wind pressures for the corner zones are compared with the design values recommended by ASCE 7-I0 and NBCC 2010. The comparisons are presented in Figure 15. The experimental values of Figure 15 are the most critical (envelope) values from all wind directions and tested buildings. The values on the dashed lines represent the external design wind pressure coefficients of ASCE 7-I0 and NBCC 2010 on roof components and cladding. Figure 15 shows that the design values recommended by ASCE 7-10 and NBCC 2010 are generally good for buildings of large size. Exceptionally, for loading areas between 2.5 and $30 \mathrm{~m}^{2}$ the ASCE 7-10 and NBCC 2010 underestimate the wind loads.

Also, the values of the most critical negative peak pressure coefficients (local loads) measured over the leading edges of the roofs are found to be in the range of -3.0 to -3.5 for all tested buildings. Furthermore, the tested roofs have experienced positive wind pressures (downward pressures) - see Figure 10. Generally, the local positive pressures (instantaneous values) are found to be in the range of 0 and +0.5 on the large roofs tested in this study. The positive pressures are comparable to the respective values of ASCE 7-10 (+0.6) and NBCC $2010(+0.5)$. 


\section{Toward Better Evaluation of Edge and Corner Zones of Large Roofs}

As a quick conclusion from the previous discussion, although the respective design pressure coefficients of ASCE 7-10 and NBCC 2010 are applicable for roof zones of large loading areas, the current provisions of ASCE 7-10 and NBCC 2010 may lead to considerably conservative and uneconomic roof systems with zones larger than the actual sizes. Some work needs to be done for the current wind provisions within this theme; therefore, some ideas will be invoked.

\section{I Modifying the current provisions of ASCE 7-10 and NBCC 2010}

The applicability of the current wind provisions for large flat roofs of low-rise buildings has been put to the test. The edge and corner zones of flat roofs recommended by ASCE 7-10 and NBCC 2010 were applied on flat roofs with large dimensions. The experimental results of the roof zones of large buildings were produced following the same pattern adopted by ASCE 7-I0 and NBCC 2010 and then compared with the respective code values. This modification can be proposed for the North American wind codes and standards.

As already noted, current guidelines of ASCE 7-10 and NBCC 2010 overestimate the roof zones of large roofs (width $\geq 120 \mathrm{~m}$ ) and very low height (height $\leq 7.5 \mathrm{~m}$ ) by applying conservative zones of areas larger than required. These zones are produced by the design criterion of $4 \%$ of the least horizontal plan dimension (0.04Ds), while for these kind of geometries, the values of roof pressure coefficients have mainly been affected by the building height. For the roof zones of ASCE 7-I0 and NBCC 2010 to hold most wind pressures of high values close to the windward roof edge, economy dictates to narrow the width of this zone as much as possible.

Under these circumstances, the results lend support to the idea that a suggestion can be proposed to make an exception to the current low building provisions for very large buildings. This exception may be added to the current guidelines defining the width of the edge zone. The current roof 
pattern and the current guidelines specified in ASCE 7-10 and NBCC 2010 are presented in Figure 16 with the proposed exception. According to Table 5 which shows the experimental roof zones sizes, it seems better to define the edge and corner zone by the ratio $0.72 \mathrm{H}$ which represents the envelope value for all ratios of $\mathrm{Z}_{\exp } / \mathrm{H}$. However, it was decided to propose $0.8 \mathrm{H}$ in order to be more conservative due to the limited configurations tested and the possible measurement error. It was indeed observed that the pressure gradients close to the windward areas of the roofs are very steep. Therefore, the envelope value has an inherent increased error. Finally, buildings with roof mean height less than $8 \mathrm{~m}$ and least horizontal dimension greater than $90 \mathrm{~m}$ have been included in this exception. The authors believe that application of this exception to current wind provisions will lead to more economic adequate design for roofs cladding of low-rise buildings with large roofs.

\subsection{Assessment of the efficiency of the proposed exception to the current provisions}

The roof zones of the current ASCE 7-10 and NBCC 2010 are compared with the modified provisions by applying the proposed exception. The comparison of the roof zones (experimental, current and modified) is presented in Table 7. Undoubtedly, the final outcomes of these code/standard provisions become more reliable against wind loading for low-rise buildings. As an illustration, for building model (B9: $180 \times 180 \times 5 \mathrm{~m}$ ), based on the modified guidelines, the size of the edge/corner zones is decreased from $7.2 \mathrm{~m}$ to $4.0 \mathrm{~m}$.

The proposed roof zones are figured on the contour of most critical peak pressure coefficient distribution over the roof perimeter of the models B8: I20XI20X5 m and B9: I80XI80X5 m of Figure 17. Clearly, the gross areas of the edge and corner zones of building model (B9) are reduced. This reduction in the size goes to the conservative portion of the roof zones created by the current provisions of ASCE 7-10 and NBCC 2010. Thus, the corner zones of the modified provisions hold all local peak pressure coefficients higher than -1.8 , whereas the corner zones of the current provisions hold all peak pressure coefficients higher than -I.3. In the same way, the edge zones of the modified 
provisions hold all local peak pressure coefficients higher than -2.0 in comparison with the edge zones of the current provisions that hold all peak pressure coefficients higher than -I.3.

Moreover, the design wind pressure coefficients provided by ASCE 7-10 and NBCC 2010 become more consistent with the actual pressure distribution on large roofs with the modified zonal system. For instance, the maximum factored local peak pressure coefficients measured on the modified interior zone are found to be ranging from - I.5 to -I.7, which are consistent with the respective design values -2.0 and -1.9 of ASCE 7-10 and NBCC 2010, respectively.

\section{Summary and Conclusions}

The paper starts by discussing the various studies they contributed to the current North American wind pressure coefficient provisions for low building roofs, particularly the roof zone areas (corner, edge, interior). These provisions originated from comprehensive studies, which dealt with different common configurations of low buildings excluding very large buildings, say 100 or $200 \mathrm{~m}$ long. Hence, the present study addressed this deficiency.

A series of wind tunnel model tests have been carried out to investigate wind-induced suctions on large flat roofs with emphasis on the generated wind loads on corner and edge zones. The present wind tunnel study has examined nine square low-rise buildings with horizontal dimensions of 60,120 and $180 \mathrm{~m}$ and heights of 5, 7.5 and $10 \mathrm{~m}$. All buildings were located in open terrain exposure and tested for several wind directions. Most of the results including pressure coefficients and roof zones have been provided in a form similar to that specified in ASCE 7-I0 and NBCC 2010.

Comparisons have been conducted to examine the adequacy of the current wind provisions of ASCE 7-I0 and NBCC 2010 with the zonal system for flat roofs of large buildings. The code definitions 
of the roof zones and design pressure coefficients have been discussed. The results and findings can be summarized as follows:

I. Building height plays a key role in impacting the values of pressure coefficients i.e. the extreme values of the roof pressure coefficients. However, the distribution patterns of roof wind pressures are mainly affected by building plan dimensions.

2. External wind pressure coefficients of ASCE 7-10 and NBCC 2010 are generally applicable for designing corner and edge zones of flat roofs. This holds true of both local and area-averaged pressure coefficients.

3. The actual sizes of the edge and corner zones of buildings with large roofs and low heights are considerably smaller than the sizes created by ASCE 7-I0 (NBCC 2010) guidelines. Thus, the ASCE 7-10 and NBCC 2010 restriction (0.04Ds) may lead to oversized edge and corner zones for such buildings.

Consequently, an exception to the general definition of the width of edge and corner zones was formulated and proposed for buildings with least horizontal dimension greater than $90 \mathrm{~m}$ and height less than $8.0 \mathrm{~m}$. This exception addresses the current problem without altering all other cases in the North American wind codes and standards.

\section{ACKNOWLEDGEMENTS}

This work was sponsored by the Natural Sciences and Engineering Research Council of Canada (NSERC). This financial support is gratefully acknowledged by the authors, who are also grateful to Professor Bert Blocken, member of the journal's Editorial Board, who kindly agreed to be Acting Editor and handled the review process for this paper outside the EVISE system, since the Editor is a co-author. 


\section{REFERENCES}

ASCE/SEI 7-I0, 20I0. Minimum Design Loads for Buildings and Other Structures. Structural Engineering Institute of ASCE, Reston, VA.

ASCE, 1999. Wind Tunnel Studies of Buildings and Structures. Manual of Practice No. 67, American Society of Civil Engineers, Reston, VA, 20191-4400, USA.

ASCE, 2012. Wind Tunnel Testing for Buildings and Other Structures. ASCE Standard (ASCE/SEI 49-12), American Society of Civil Engineers, Reston, VA, 20191, USA.

AS/NZS II 70.2 (20II) Australian/New Zealand Standard for Structural Design Actions, part 2: Wind Actions. Sydney, New South Wales, Australia: Standards Australia and Standards New Zealand.

Barnaud, G., Gandemer, J., 1974. Determination en Soufflerie Simulant le Vent Naturel des Coefficients de Pression sur les Structures Basses. Section Aerodynamique des Constructions ADYM-12.74, Centre Scientifique et Technique du Batiment, Etablissement de Nantes.

Cochran, L.S., Cermak, J.E., 1992. Full- and Model-Scale Cladding Pressures on the Texas Tech Experimental Building. Journal of Wind Engineering and Industrial Aerodynamics, 43, I589-1600.

Davenport A.G., 1983. On the Assessment of the Reliability of Wind Loading on Low Buildings. Journal of Wind Engineering and Industrial Aerodynamics, II, 21 -37.

Davenport, A. G., Surry, D., 1974. Pressures on Low Rise Structures in Turbulent Wind. Presented at the Canadian Structural Engineering Conference, Toronto.

Davenport, A.G., Surry, D., Stathopoulos, T, 1977. Wind Loads on Low-Rise Buildings, Final Report on Phases I and II. BLWT-SS7, The University of Western Ontario, London, Ontario, Canada.

Davenport, A.G., Surry, D., Stathopoulos, T, 1978. Wind Loads on Low-Rise Buildings, Final Report on Phase III. BLWT-SS8, The University of Western Ontario, London, Ontario, Canada.

Eaton, K.J., Mayne, J.R., 1975. The Measurements of Wind Pressures on Two-Story Houses at Aylesbury. Journal of Wind Engineering and Industrial Aerodynamics, I (I), 67-I09.

Elsharawy, M., Galal, K., Stathopoulos, T., 2014. Comparison of Wind Tunnel Measurements with NBCC 2010 Wind-induced Torsion Provisions for Low- and Medium-rise Buildings. Canadian Journal of Civil Engineering, 4I(5), 409-420.

EN 199I-I-4, 2005. Eurocode I, 2005: Actions on Structures-General actions-Part I-4: Wind Actions, European Standard.

Gerhardt, H. J., Kramer, C., 1992. Effect of Building Geometry on Roof Wind Loading, Journal of Wind Engineering and Industrial Aerodynamics, 43, I765-1773.

Geurts, C.P.W, Bentum, C.V., 2007. Wind Loading on Buildings: Eurocode and Experimental Approach, in T. Stathopoulos and C.C. Baniotopoulos, Wind Effects on Buildings and Design of Wind-Sensitive Structures, New York, pp. 31-65, Springer.

Hellers, G., Lundgren, S., 1974. Wind Loads on Generally Shaped House Bodies-Model Tests. Report R22: 1974, National Swedish Building Research Summaries.

Hillier, R., 1973. An Investigation of the Cladding Wind Loads on Model of Hartlepool Switch House. CERL Report RDL/N227/73, Central Electricity Research Laboratories, Surrey, England.

Ho, T.C.E., Surry, D., Morrish, D., Kopp, G.A., 2005. The UWO Contribution to the NIST Aerodynamic Database for Wind on Low Buildings: Part I. Archiving Format and Basic Aerodynamic Data. Journal of Wind Engineering and Industrial Aerodynamics, 93, I-30.

Holmes, J.D., 1993.Wind Loads on Low-rise Buildings - A Review. CSIRO, Division of Building Research, Highett, Victoria, Australia. 
Holmes, J.D., 200I. Wind Loading of Structures, Spon Press London, New York.

Holmes, J. D., Best, R.J., 1978. Wind Pressures on an Isolated High-Set House. James Cook University of North Queensland, Australia, Wind Engineering Report 3/78, Qeensland, Australia.

Hosoya, N., Cermak, J.E., Dodge, S.M., 1999. Area-Averaged Pressure Fluctuations on Surfaces at Roof Corners and Gable Peaks. Proceedings of the Tenth International Conference on Wind Engineering, Copenhagen, Denmark, I779-I785.

Jensen, M., Franck, N., 1965. Model-Scale Tests in Turbulent Wind, Parts I and II. The Danish Technical Press, Copenhagen.

Kasperski, M., 1996. Design Wind Loads for Low-rise Buildings: A Critical Review of Wind Load Specifications for Industrial Buildings. Journal of Wind Engineering and Industrial Aerodynamics, 6I, 169- 179.

Kramer, C., Gerhardt, H. J., 1975. Windbelastung auf Flachdachern. Published in Das Dechdeckerhandwerk, Koln. 96, 16.

Krishna, P., 1995. Wind Loads on Low Rise Buildings - A Review. Journal of Wind Engineering and Industrial Aerodynamics, 54-55, 383-396.

Lin, J.X., Surry, D., 1998. The Variation of Peak Loads With Tributary Area Near Corners on Flat Low Building Roofs. Journal of Wind Engineering and Industrial Aerodynamics, 77-78, 185-196

Lin, J.X., Surry, D., Tieleman, H.W., 1995. The Distribution of Pressure Near Roof Corners of Flat Roof Low Buildings. Journal of Wind Engineering and Industrial Aerodynamics, 56, 235-265.

Marshall, R. D., 1974. A Study of Wind Pressures on a Single-Family Dwelling in Model and Full Scale. Proceedings of the Invitational Symposium on Full Scale Measurements of Wind Effects on Tall Buildings and Other Structures. Boundary Layer Wind Tunnel Laboratory, The University of Western Ontario, Canada, June 23-29.

Marshall, R.D., 1977. The Measurement of Wind Loads on a Full-Scale Mobile Home. National Bureau of Standards, U.S. Dep. of Commerce, Washington, D.C., NBSIR 77-I289.

Milford, R.V., Goliger, A.M., Waldech, J.L., 1992. Jan Smuts Experiment: Comparison of Full-Scale and WindTunnel Results. Journal of Wind Engineering and Industrial Aerodynamics, 43, 1693-1704.

Morrison, M.J., Kopp, G.A., 2007. Evaluation of the ASCE 7-05 Definition of Edge and Corner Zones for LowRise Buildings. The Boundary Layer Wind Tunnel Laboratory, The University of Western Ontario, Faculty of Engineering, London, Ontario, Canada N6A 5B9.

NBC2010, 2010. User's Guide-NBC 2010, Structural Commentaries (Part 4). Issued by the Canadian Commission on Buildings and Fire Codes, National Research Council of Canada.

Peterka, J.A., Hosoya, N., Dodge, S., Cochran, L.S., Cermak, J.E., 1998. Area Average Peak Pressures in a Gable Roof Vortex Region. Journal of Wind Engineering and Industrial Aerodynamics, 77-78, 205-2I5.

Pierre, L.M. St., Kopp, G.A., Surry, D., Ho, T.C.E., 2005. The UWO Contribution to the NIST Aerodynamic Database for Wind on Low Buildings: Part 2. Comparison of Data with Wind Load Provisions. Journal of Wind Engineering and Industrial Aerodynamics, 93, 31-59.

Simiu, E., Scanlan, R.H., 1996. Wind effects on structures, third edition Wiley and Sons, New York.

Stathopoulos, T., 1975. Wind Pressure Loads on Flat Roofs. BLWT Report 3-1975, The University of Western Ontario, London, Ontario, Canada.

Stathopoulos, T., 1979. Turbulent Wind Action on Low-rise Buildings. Ph.D. Thesis, The University of Western Ontario, London, Ontario, Canada.

Stathopoulos, T., 198I. Wind Loads on Eaves of Low Buildings. Journal of the Structural Division, ASCE, 107(10), 1921-1934. 
Stathopoulos, T., 1984-A. Design and Fabrication of a Wind Tunnel for Building Aerodynamics. Journal of Wind Engineering and Industrial Aerodynamics, 16, 36I-376.

Stathopoulos, T., 1984-B. Wind Loads on Low-rise Buildings - A Review of the State of the Art, Engineering Structures, 6, 119-135.

Stathopoulos, T., Dumitrescu-Brulotte, M., 1989. Design Recommendations for Wind Loading on Buildings of Intermediate Height. Canadian Journal of Civil Engineering, 16, 910-916.

Stathopoulos, T., Luchian, H.D., 1990. Wind Pressures on Buildings Configurations with Stepped Roofs. Canadian Journal of Civil Engineering, I7(4), 569-577.

Stathopoulos, T., Luchian, H., 1992. Wind-Induced Forces on Eaves of Low Buildings. Wind Engineering Society Inaugural Conference, Cambridge, England.

Stathopoulos, T., Saathoff, P., 199I. Wind Pressures on Roofs of Various Geometries. Journal of Wind Engineering and Industrial Aerodynamics, 38, 273-284.

Stathopoulos, T., Surry, D., 1983. Scale Effects in Wind Tunnel Testing of Low Buildings. Journal of Wind Engineering and Industrial Aerodynamics, 13, 313-326.

Stathopoulos, T., Zhu, X., 1988. Wind Pressures on Buildings with Appurtenances. Journal of Wind Engineering and Industrial Aerodynamics, 3I, 265-28I.

Stathopoulos, T., Kumar, K.S., Mohammadiam, A.R., 1996. Design Wind Pressure Coefficients for Monoslope Roofs: A Time Series Approach. Journal of Wind Engineering and Industrial Aerodynamics, 65, I43-I53.

Surry, D., Kitchen, R. B., Davenport, A. G., 1977. Wind Loading of Two Hangars Proposed for Jeddah Airport, Saudi Arabia - A Rigid Model Study. Report unpublished, Boundary Layer Wind Tunnel Laboratory, The University of Western Ontario, London, Ontario, Canada.

Surry, D., Stathopoulos, T., 1978. An Experimental Approach to the Economical Measurements of Spatially Averaged Wind Loads. Journal of Wind Engineering and Industrial Aerodynamics, 2 (4), 385-97.

Uematsu, Y., Isyumov, N., 1999. Wind Pressures Acting on Low-Rise Buildings. Journal of Wind Engineering and Industrial Aerodynamics, 82, I-25.

Vickery, B. J., 1976. Wind Loads on Low-Rise Buildings. Presented at D.R.C Seminar, Darwin, March 30, Unpublished.

Wiren, B., 197I. Wind Tunnel Investigation of the Pressure Distribution on a Flat Roof with Different Edge Profiles. Translated From the Swedish, Library Communication 1606, Building Research Station. 


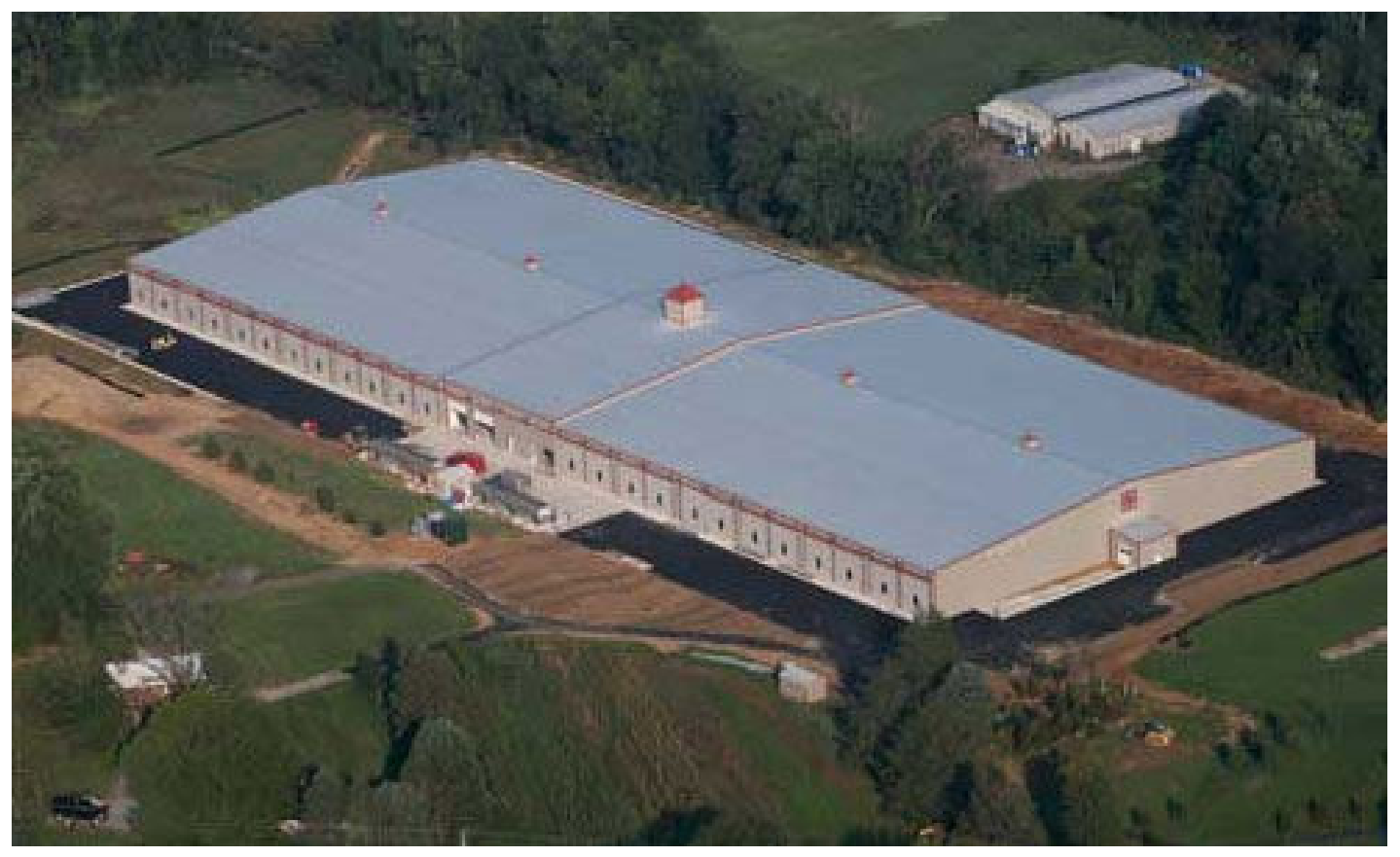

Figure I: Large Low-rise building: The Mushroom warehouse, located in Southeastern Pennsylvania, U.S.A (http://www.constructionmagnet.com/rural-builder/post-frame-phenom-for-fungi). 
NBCC 2010:

$h<10 \mathrm{~m}$, or $\mathrm{h}<20 \mathrm{~m}$ with $\mathrm{h}<\mathrm{B}$. $0^{\circ} \leq \boldsymbol{\alpha} \leq \mathbf{7}^{\circ}$.

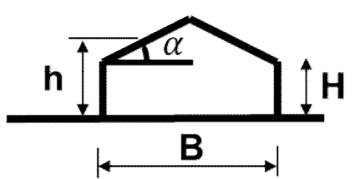

ASCE 7-10:

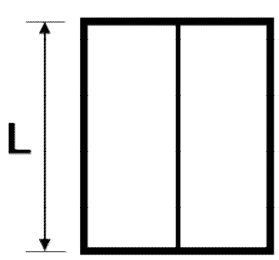

EN |99|-|-4:2005:

$\mathrm{h}<\mathrm{I} 5 \mathrm{~m}$.

$-5^{\circ} \leq \alpha \leq 5^{\circ}$

AS-NZS 1170-2, 2011:

$\mathrm{h}<25 \mathrm{~m}$.

$0^{\circ} \leq \alpha \leq 10^{\circ}$

Figure 2: Flat-roofed low-rise building definitions in different wind standards and codes of practice. 

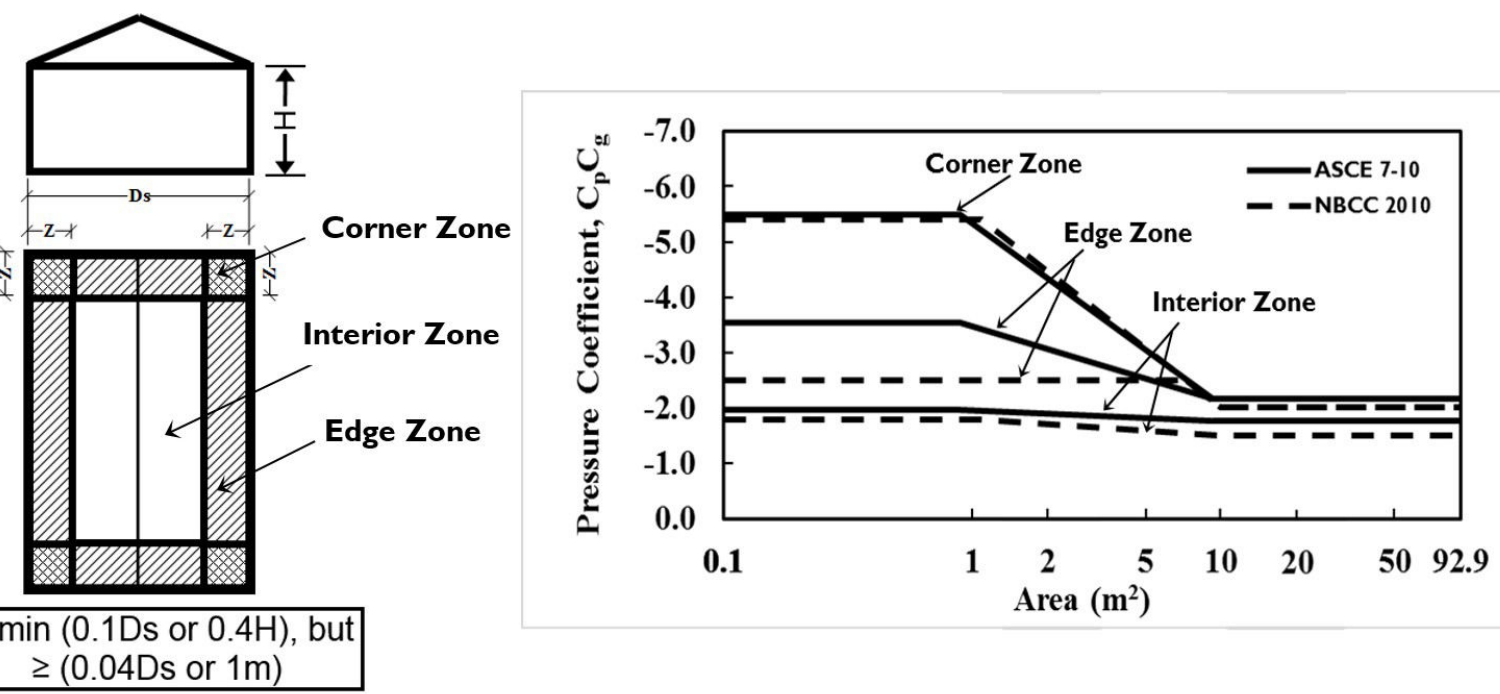

$\mathrm{Z}=\min (0.1 \mathrm{Ds}$ or $0.4 \mathrm{H})$, but $\geq(0.04 \mathrm{Ds}$ or $1 \mathrm{~m})$

\section{Ds: Minimum horizontal dimension}

H: Eave height

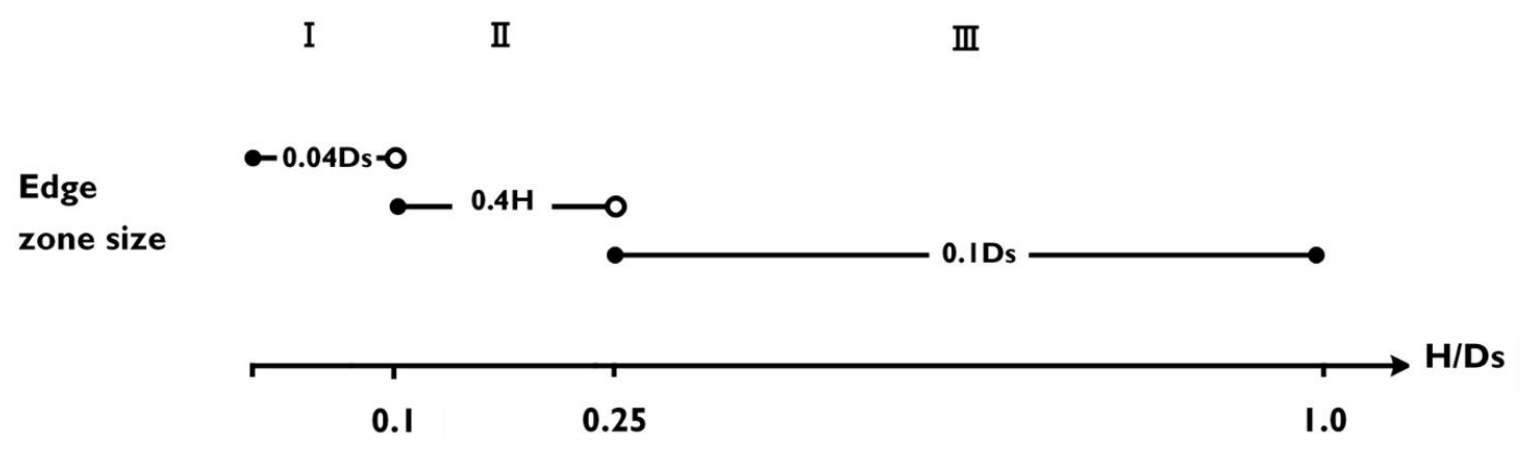

Figure 3: Roof zones and external peak pressure coefficients, $\mathrm{Cp} C$, on edge, corner, and interior zones of building roofs with a slope of $7^{\circ}$ or less in ASCE 7-10 and NBCC 2010. 


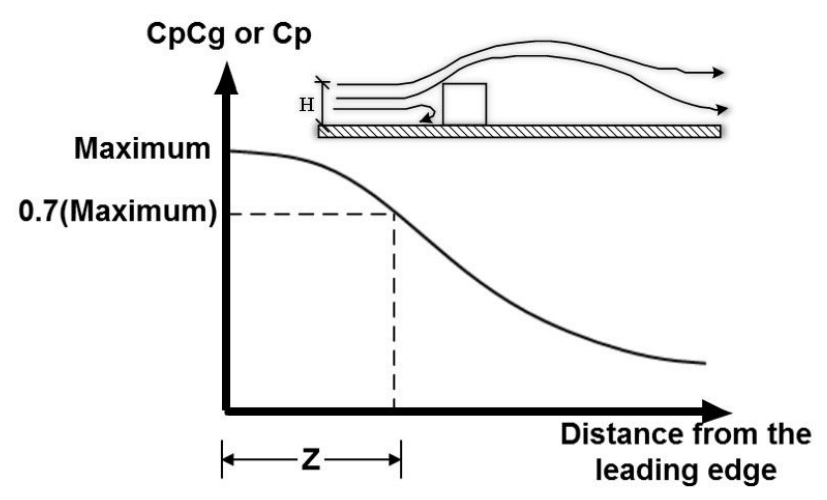

a)

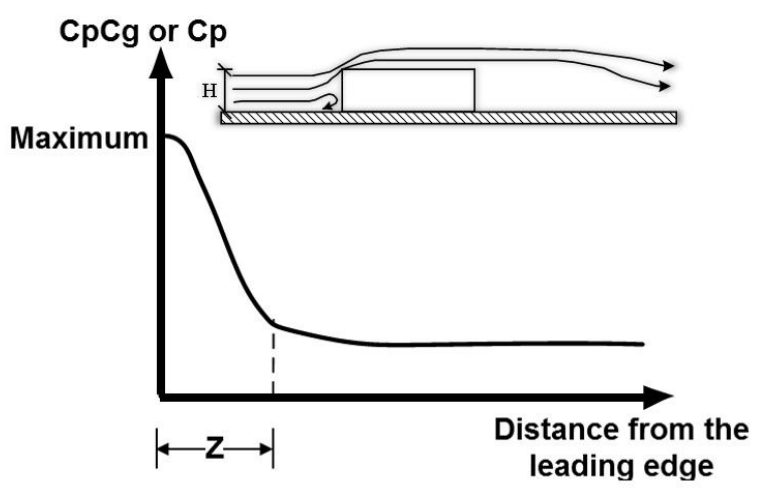

b)

Figure 4: Mean and negative peak pressure distribution curves over the roofs of the buildings:

a) Smaller roofs, b) Larger roofs. 


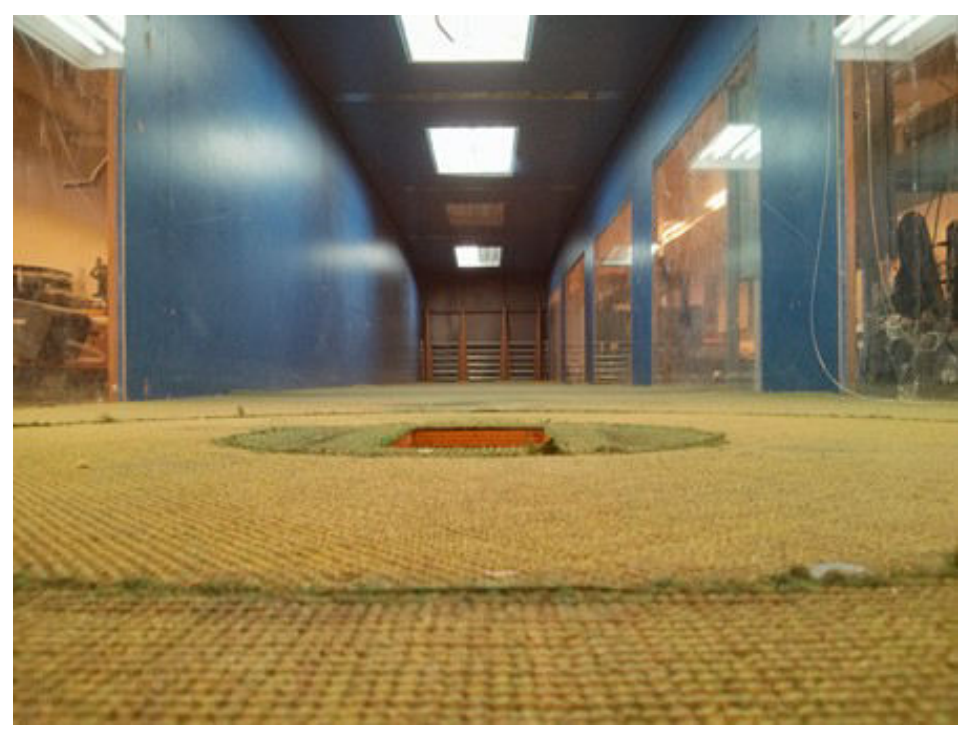

Figure 5: Boundary layer wind tunnel at Concordia University (Front view). 


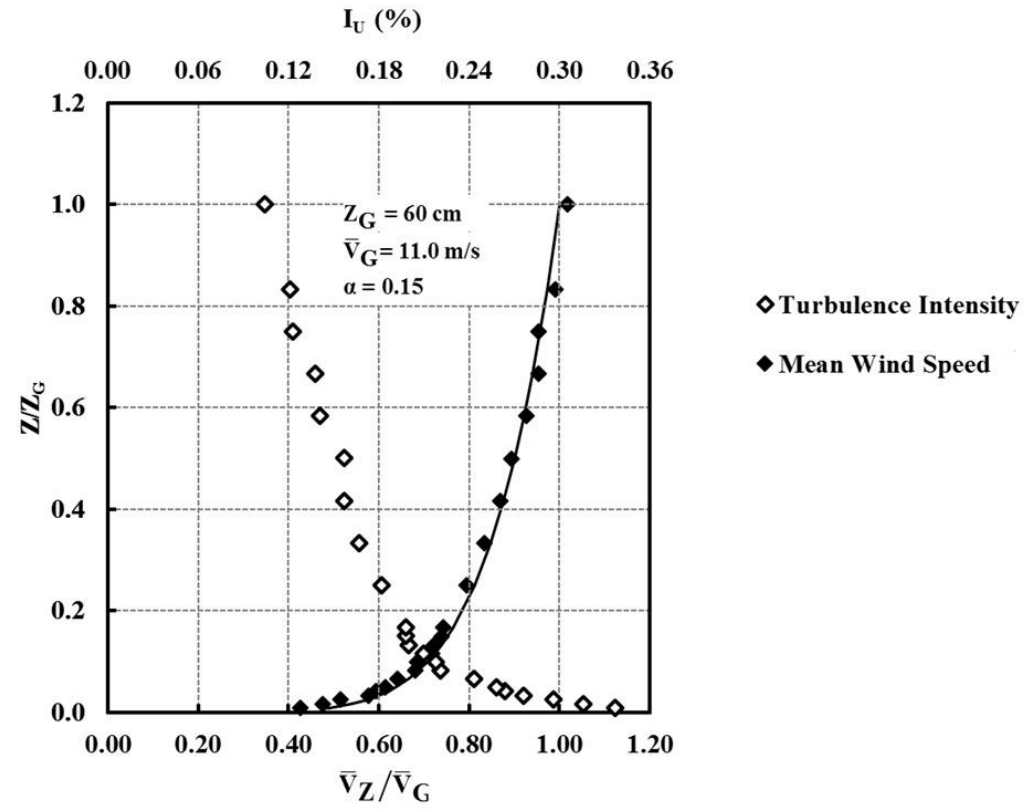

Figure 6: Vertical distribution of mean wind speed and longitudinal turbulence intensity for open country exposure $\left(\bar{V} / V_{G}=\left(Z / Z_{G}\right)^{0.15}\right)$. 


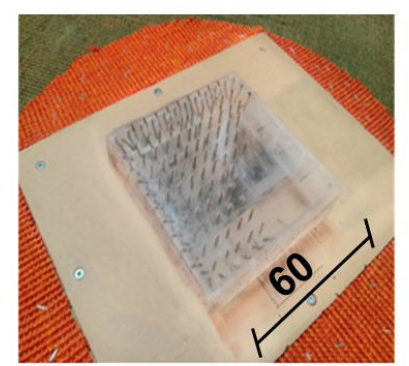

a)

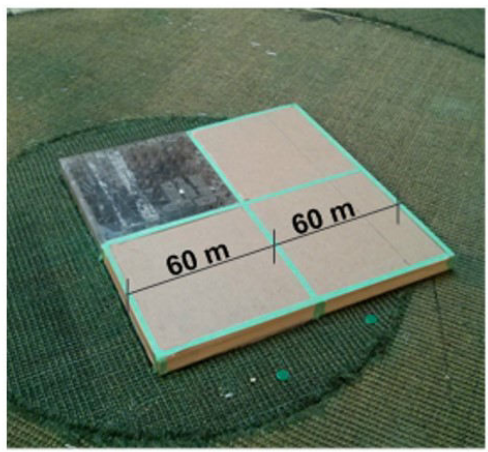

b)

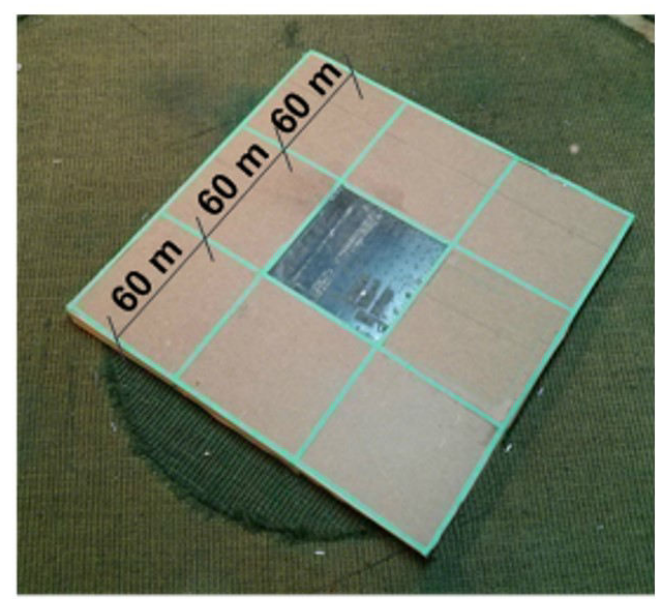

c)

Figure 7: Typical building models with equivalent full-scale square plan dimensions tested in the wind tunnel: a) $60 \mathrm{~m}$, b) $120 \mathrm{~m}$ and c) $180 \mathrm{~m}$. 

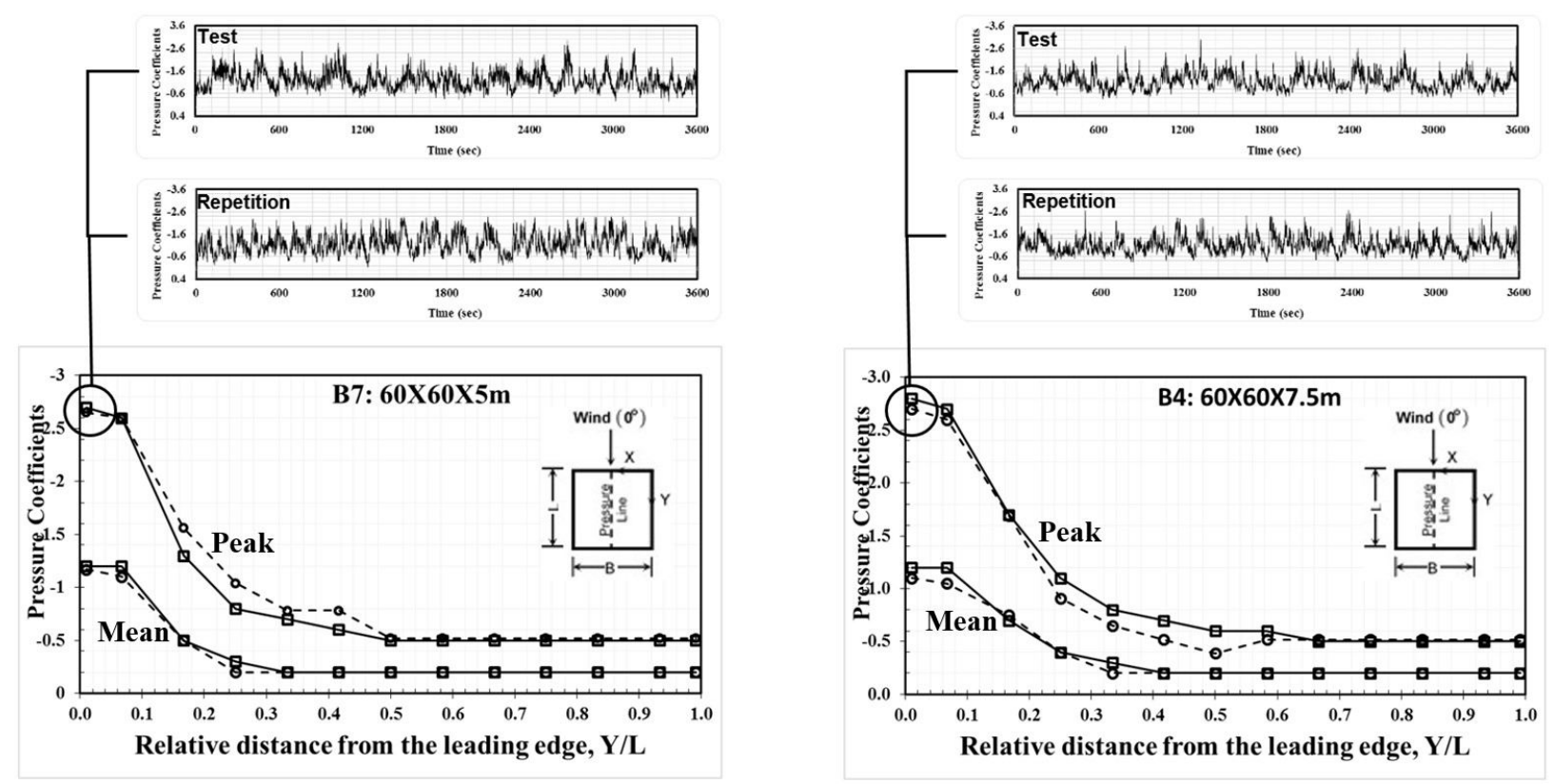

$\rightarrow$ Original results

- - -Repeatability results

Figure 8: Mean and peak pressure coefficient distributions for buildings B7 and B4 with their time histories at an edge point measured in two tests with the same flow characteristics. 

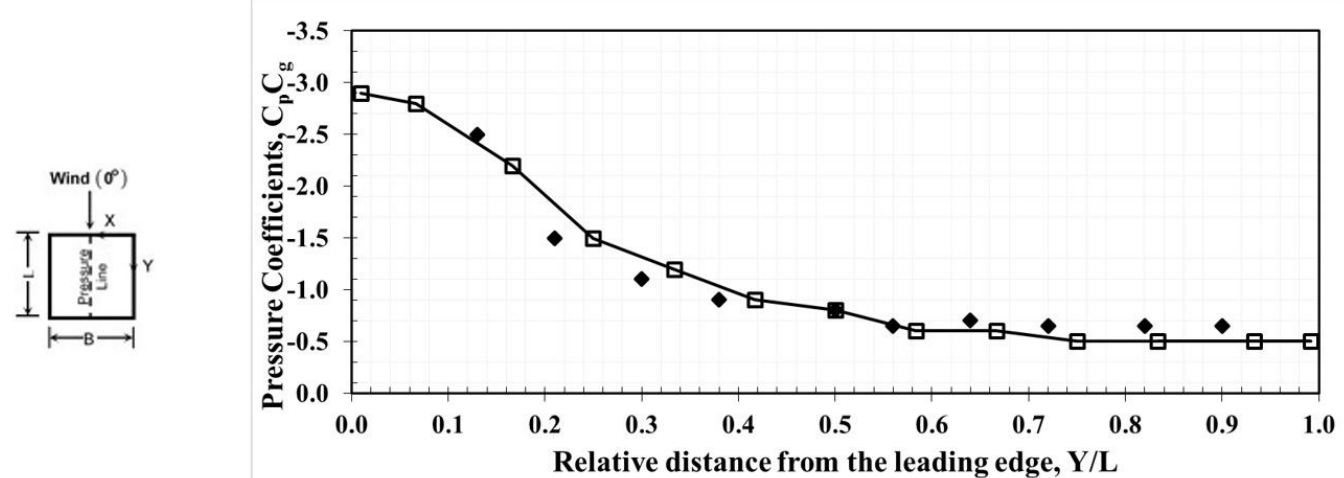

(a)

(b)

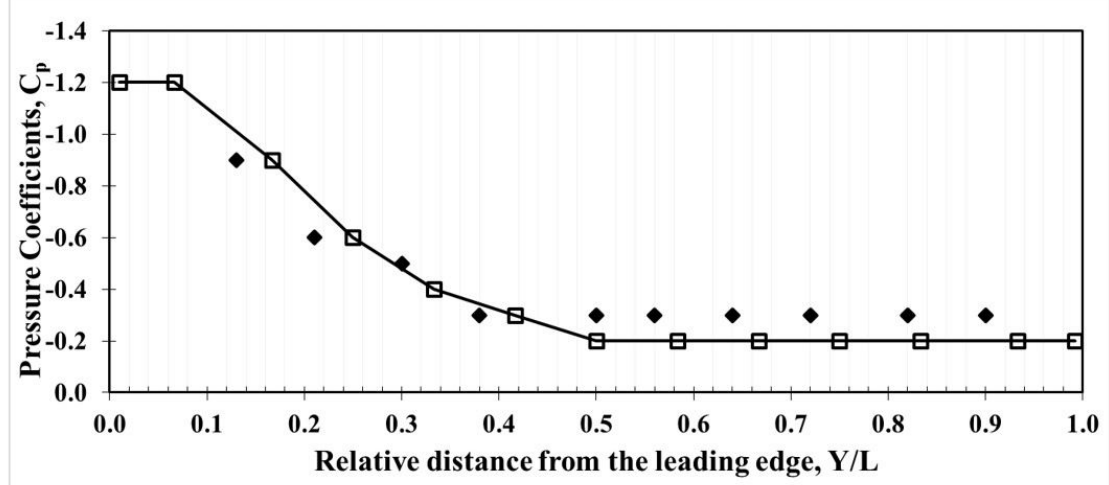

(c)

屯B1: 60X60X10 m

- Stathopoulos and Dumitrescu-Brulotte (1989)

Figure 9: Pressure coefficient distributions for building BI in comparison with data of Stathopoulos and Dumitrescu-Brulotte (1989) measured with similar flow conditions: (a) Location of pressure taps, (b) Peak pressure coefficients, $\mathrm{CpCg}$ and (c) Mean pressure coefficients, $C_{p}$. 


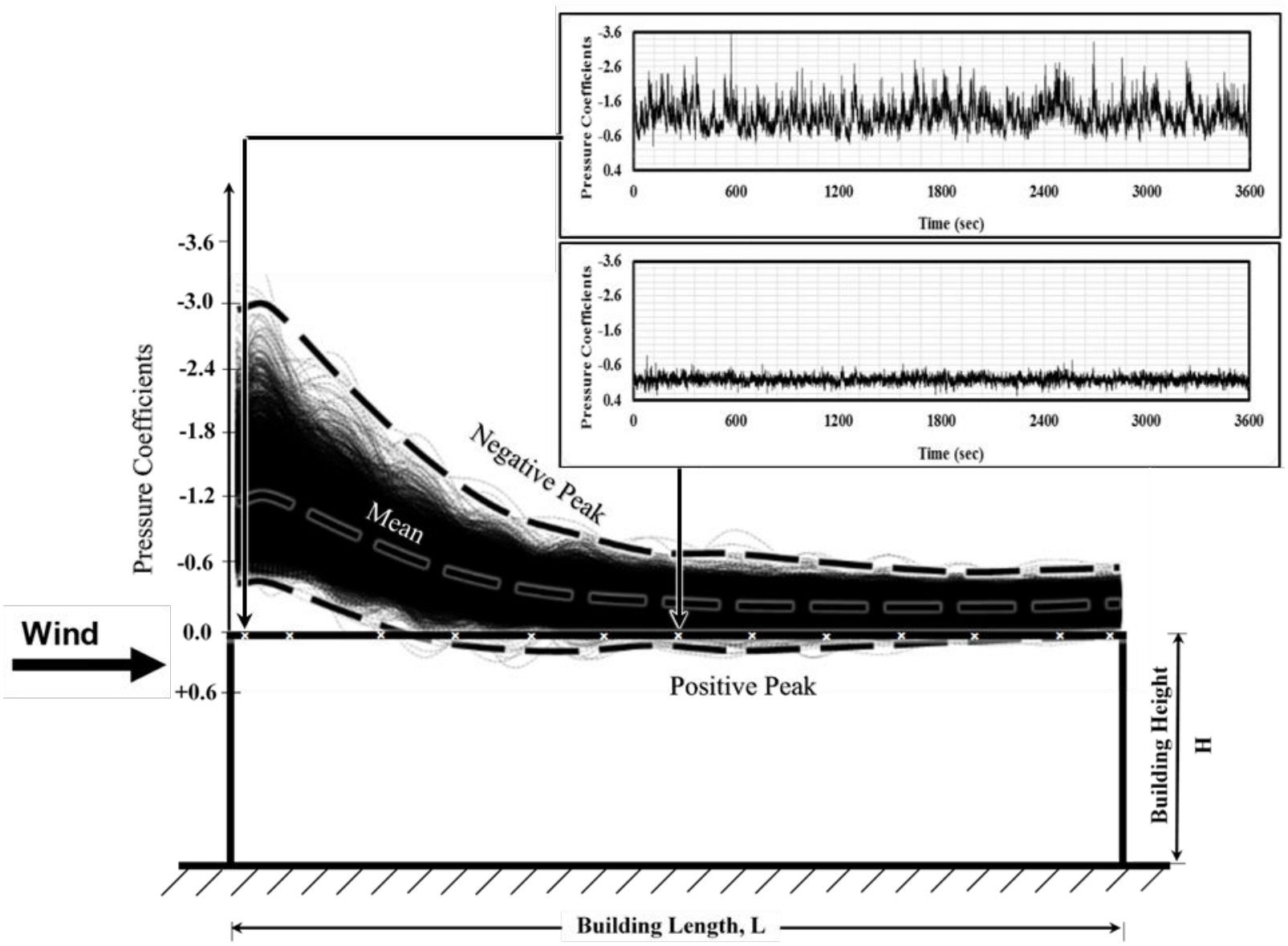

Figure 10: Instantaneous pressure coefficient distributions and negative peak, mean and positive peak values on a typical large flat roof; pressure tap locations are indicated by the symbol, $\mathbf{x}$. 


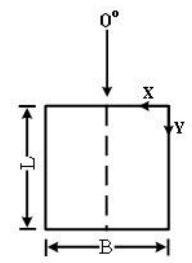

a)

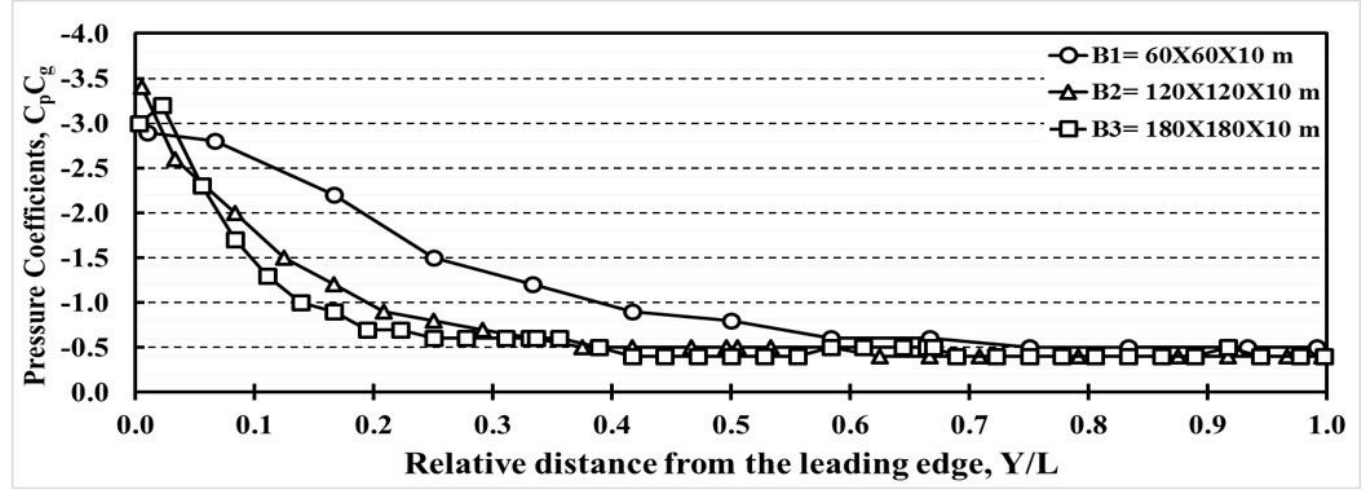

b)

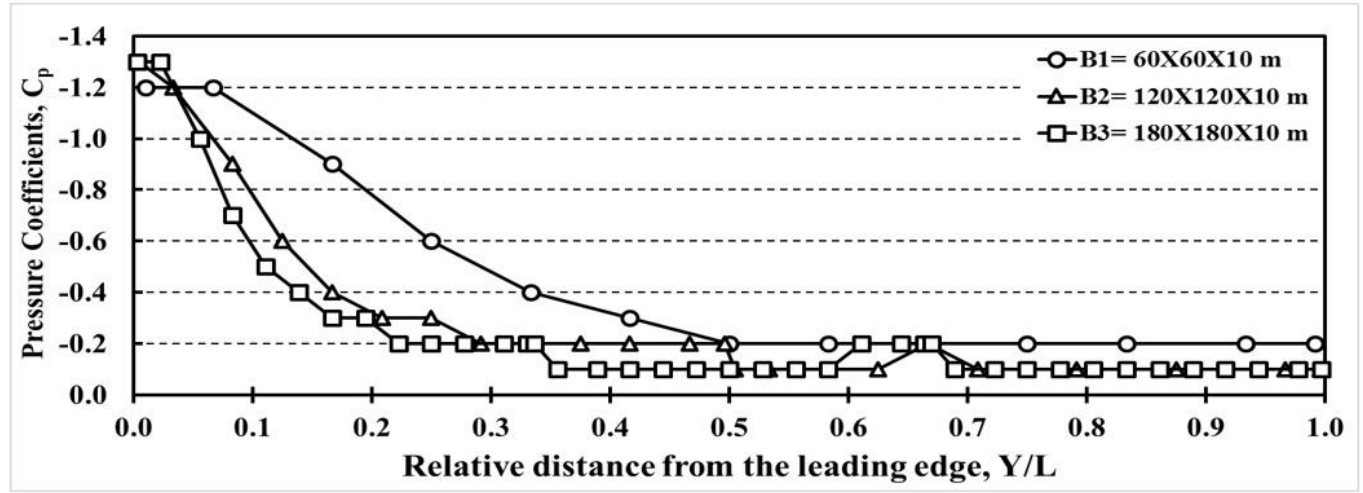

c)

Figure I I: Variation of negative pressure coefficients along the mid-roof line of the 10-m high buildings for $0^{\circ}$ : (a) Model plan view and pressure tap line locations, (b) Peak pressure coefficients, $C_{p} C_{g}$ and (c) Mean pressure coefficients, $C_{p}$. 


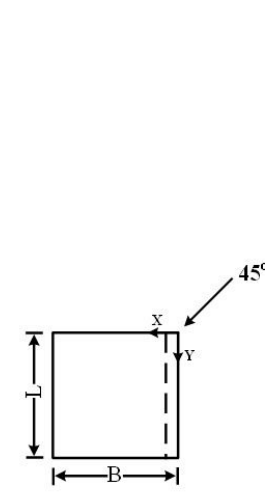

a)

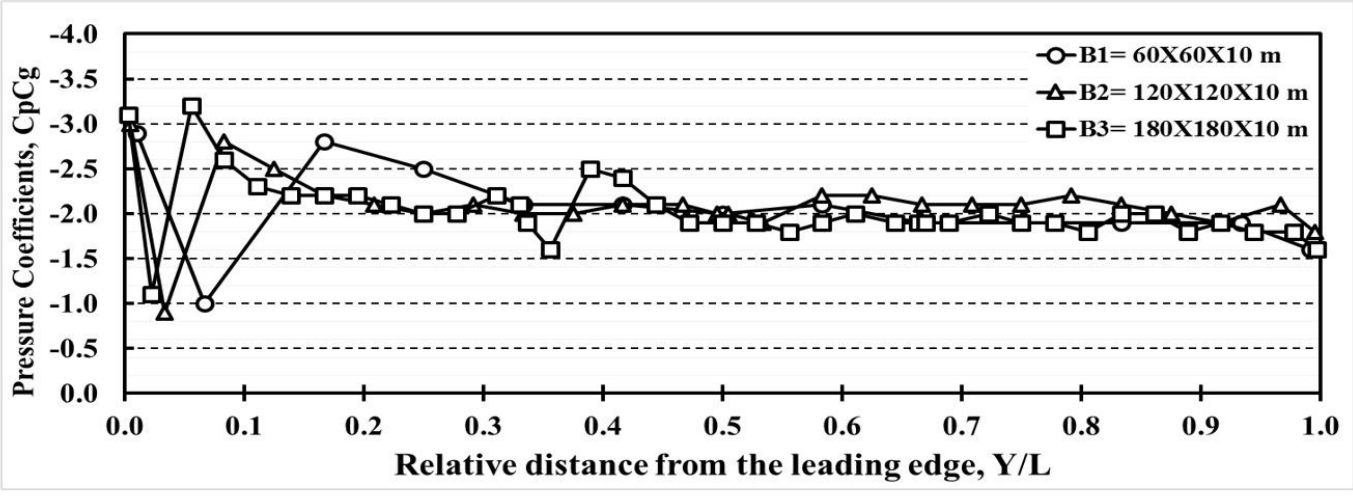

b)

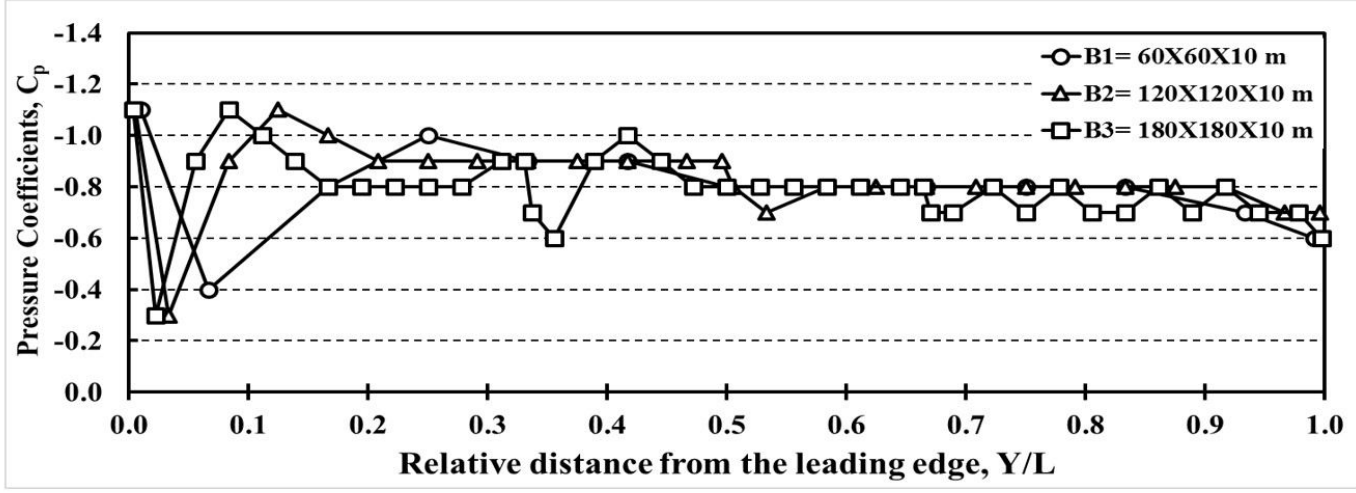

c)

Figure 12: Variation of negative pressure coefficients along the roof edge line of the 10-m high building for $45^{\circ}$ : (a) Model plan view and pressure tap line locations, (b) Peak pressure coefficients, $C_{p} C_{g}$ and (c) Mean pressure coefficients, $C_{p}$. 


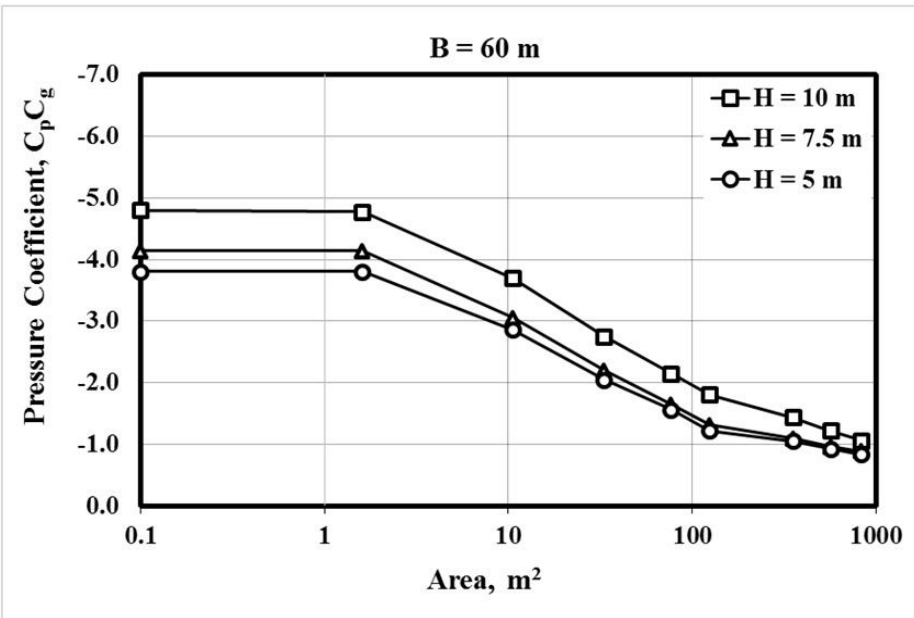

a)

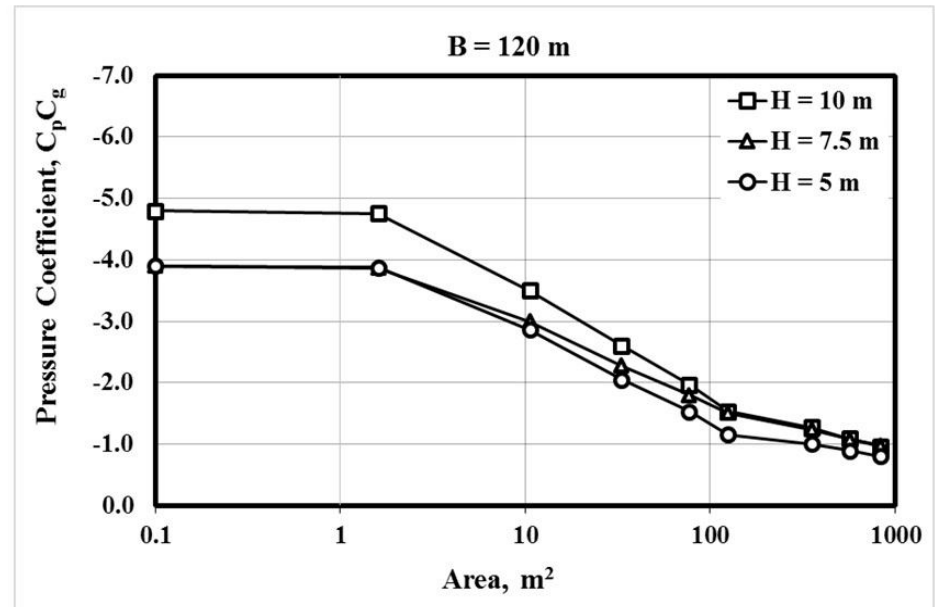

b)

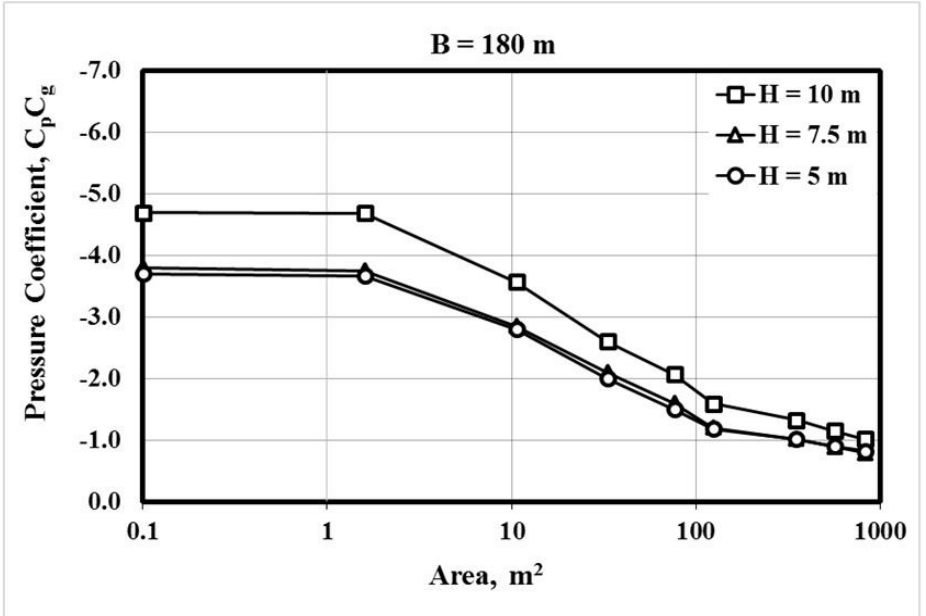

c)

Figure 13: Variation of the most critical area-averaged pressure coefficients, $\mathrm{Cp}_{\mathrm{pg}}$, for the roof corner zone with tributary area for buildings of horizontal plan width of: (a) $60 \mathrm{~m}$, (b) $120 \mathrm{~m}$ and (c) $180 \mathrm{~m}$. 


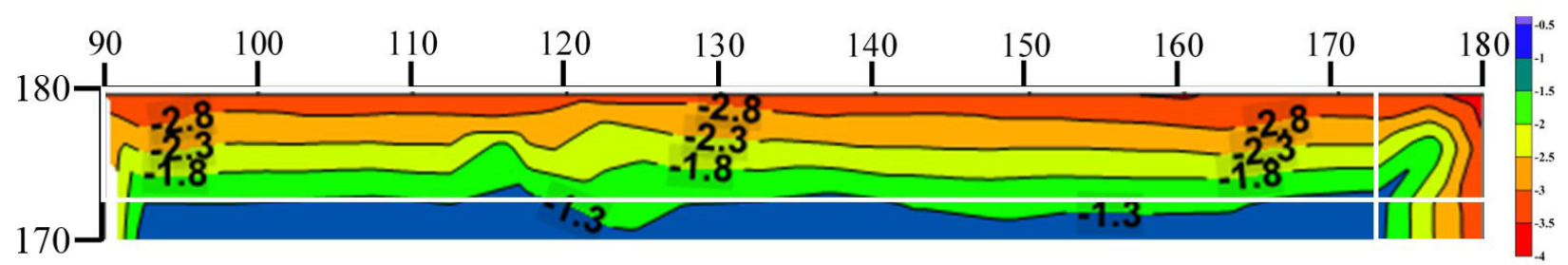

ASCE 7-IO (NBCC 2010), $7.2 \mathrm{~m}$

(a)

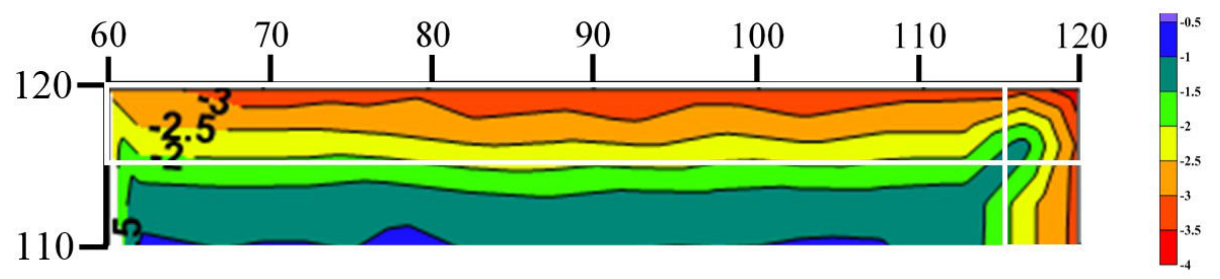

ASCE 7-IO (NBCC 2010), $4.8 \mathrm{~m}$

(b)

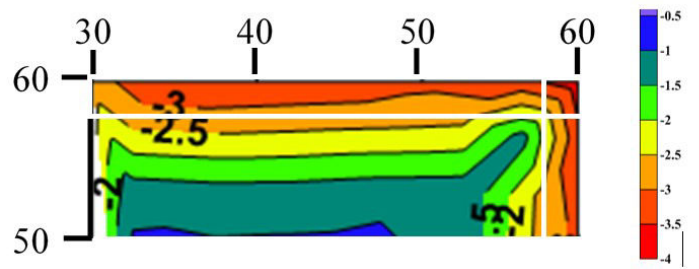

ASCE 7-IO (NBCC 2010), $2.4 \mathrm{~m}$

(c)

Figure 14: Most critical negative peak pressure coefficient contours (envelope for all wind directions) with roof zones of the current provisions of ASCE 7-10 and NBCC 2010 for buildings: (a) B9: 180X180X5, (b) B8: $120 \times 120 \times 5$ and (c) B7: $60 \times 60 \times 5 \mathrm{~m}$. 


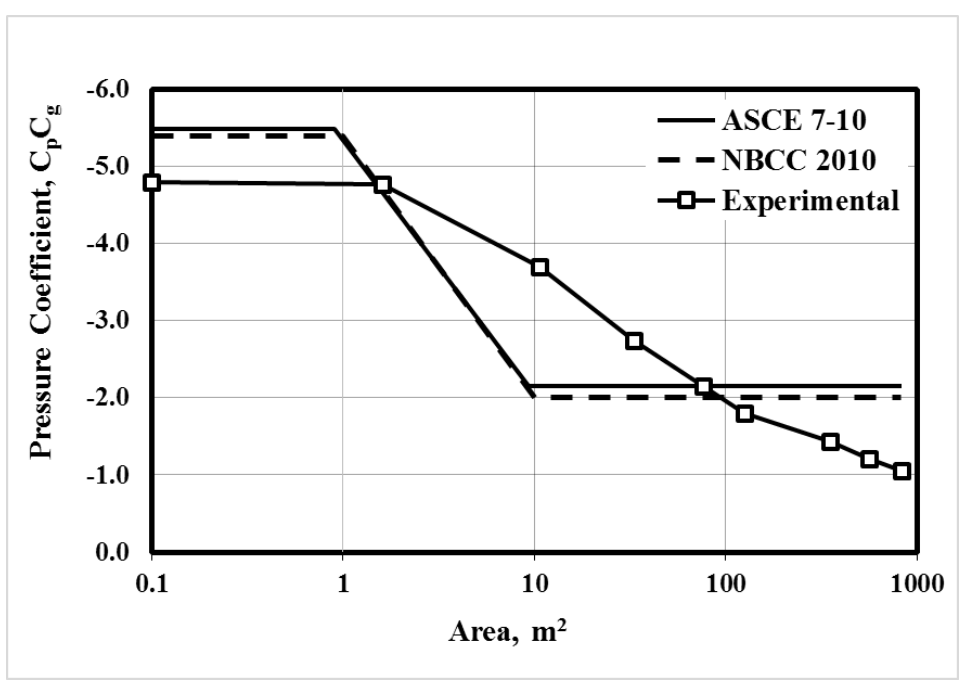

Figure 15: Comparison of most critical pressure coefficients, $\mathrm{CpCg}$, measured with recommended code values for the roof corner zone. 


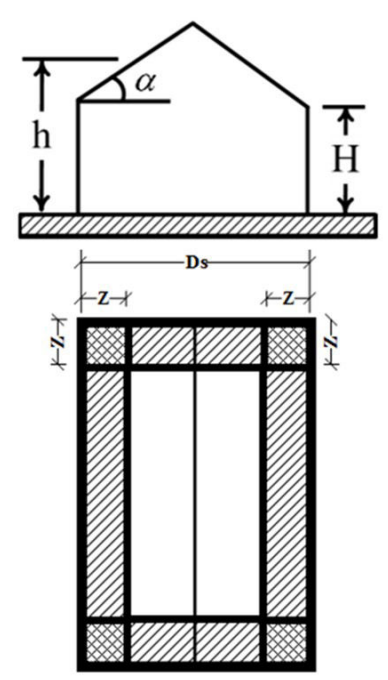

"End-zone width $z$ is the lesser of $10 \%$ of the least horizontal dimension and $40 \%$ of the height, h, but not less than $4 \%$ of the least horizontal dimension or Im". (NBCC 2010).

Exception: for roofs of buildings with $\alpha=0^{\circ}$ to $7^{\circ}, \mathrm{h}$ less than $8 \mathrm{~m}$ and a least horizontal dimension greater than $90 \mathrm{~m}$ the edge zone width shall be limited to a maximum of $(0.8 \mathrm{~h})$.

Figure 16: The current roof system specified in ASCE 7-10 and NBCC 2010 with the proposed exception. 


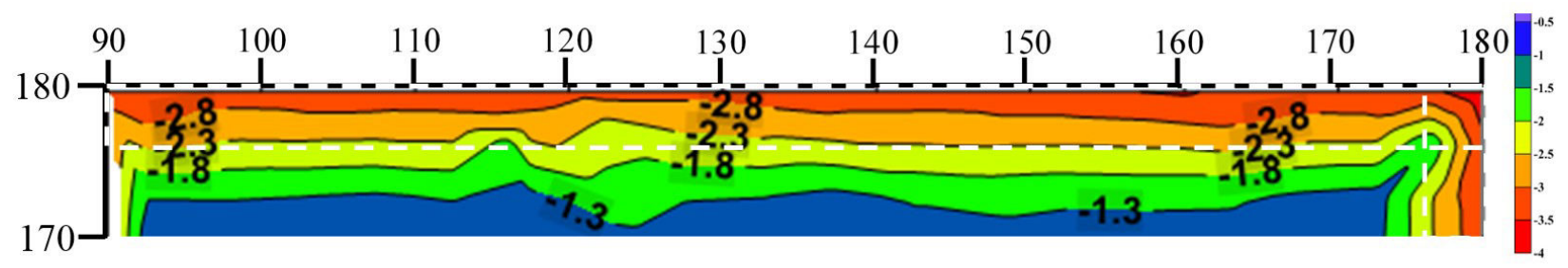

- - - - Modified provisions, $4.0 \mathrm{~m}$

(a)

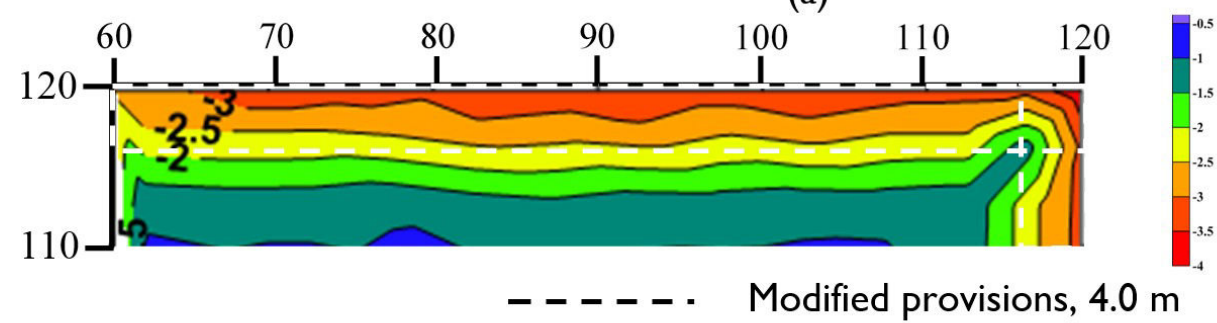

(b)

Figure 17: Most critical negative peak pressure coefficient contours (envelope values for all wind directions) with roof zones determined by the proposed provisions for buildings: (a) B9: $180 \times 180 \times 5$ and (b) B8: $120 \times 120 \times 5$ 


\begin{tabular}{|c|c|c|c|c|}
\hline & $\begin{array}{l}\text { ASCE } \\
7-10\end{array}$ & $\begin{array}{l}\text { NBCC } \\
2010\end{array}$ & $\begin{array}{c}\text { EN } 199|-|-4 \\
2005\end{array}$ & $\begin{array}{c}\text { AS-NZS II } \\
2010-2\end{array}$ \\
\hline $\begin{array}{c}\text { Basic wind } \\
\text { speed }\end{array}$ & V & V & $\mathrm{V}=\mathrm{V}_{\mathrm{b}, \mathrm{o}} \mathrm{C}_{\text {dir }} \mathrm{C}_{\text {seas }}$ & $\mathrm{V}=\mathrm{V}_{\mathrm{R}} \mathrm{M}_{\mathrm{d}} \mathrm{M}_{\mathrm{z}, \mathrm{cat}} \mathrm{M}_{\mathrm{s}} \mathrm{M}_{\mathrm{t}}$ \\
\hline $\begin{array}{c}\text { Velocity } \\
\text { pressure, } q \\
\end{array}$ & $0.5 \rho \mathrm{V}^{2} \mathrm{~K}_{\mathrm{z}} \mathrm{K}_{\mathrm{zt}} \mathrm{K}_{\mathrm{d}} \mathrm{I}$ & $0.5 \rho V^{2} \mathrm{I}$ & $0.5 \rho V^{2}$ & $0.5 \rho V^{2}$ \\
\hline $\begin{array}{l}\text { Design building } \\
\text { pressure }\end{array}$ & $\mathrm{q}\left(\mathrm{GC}_{\mathrm{p}}\right)$ & $\mathrm{qC}_{\mathrm{e}}\left(\mathrm{C}_{\mathrm{g}} \mathrm{C}_{\mathrm{p}}\right)$ & $\mathrm{qC}_{\mathrm{e}} \mathrm{C}_{\mathrm{p}, \mathrm{e}}$ & $\mathrm{qK}_{\mathrm{a}} \mathrm{K}_{\mathrm{c}, \mathrm{e}} \mathrm{K}_{\mathrm{l}} \mathrm{K}_{\mathrm{p}}\left(\mathrm{C}_{\mathrm{p}, \mathrm{e}}\right)$ \\
\hline Terrain factor & $\mathrm{K}_{\mathrm{z}}$ & $\mathrm{C}_{\mathrm{e}}$ & $\mathrm{C}_{\mathrm{r}}$ & $\mathrm{M}_{\mathrm{z}, \mathrm{cat}}$ \\
\hline $\begin{array}{c}\text { Topographic } \\
\text { factor } \\
\end{array}$ & $\mathrm{K}_{\mathrm{zt}}$ & $\mathrm{C}_{\mathrm{e}}^{*}$ & $\mathrm{C}_{\mathrm{o}}$ & $\mathrm{M}_{\mathrm{t}}$ \\
\hline $\begin{array}{l}\text { Directionality } \\
\text { factor }\end{array}$ & $\mathrm{K}_{\mathrm{d}}$ & - & $\mathrm{C}_{\mathrm{dir}}$ & $\mathrm{M}_{\mathrm{d}}$ \\
\hline $\begin{array}{c}\text { Basic wind } \\
\text { speed averaging } \\
\text { time }\end{array}$ & $3 \mathrm{~s}$ & $\mathrm{I} \mathrm{h}$ & $10 \mathrm{~min}$ & $3 \mathrm{~s}$ \\
\hline $\begin{array}{l}\text { Wind velocity } \\
\text { profile }\end{array}$ & $\begin{array}{l}\text { Logarithmic law } \\
\text { Power law }\end{array}$ & Power law & Logarithmic law & Logarithmic law \\
\hline
\end{tabular}

When the topographic factor is used in NBCC, $C_{e}^{*}$ is placed instead of $C_{e}$.

$\mathrm{C}_{\mathrm{e}}$ : Exposure factor defined as follows: $\mathrm{C}_{\mathrm{e}}=\left[1+7 \mathrm{I}_{\mathrm{V}}\right] \mathrm{C}_{\mathrm{r}}^{2} \mathrm{C}_{\mathrm{o}}^{2}$, in which $\mathrm{I}_{\mathrm{V}}$ is the turbulence intensity.

$\mathrm{C}_{\mathrm{p}}$ and $\mathrm{C}_{\mathrm{p}, \mathrm{e}}$ : External pressure coefficient. $\mathrm{C}_{\text {seas }}$ : Seasonal factor.

$\mathrm{G}$ and $\mathrm{C}_{\mathrm{g}}$ : Gust effect factor.

I : Turbulence intensity.

$\mathrm{K}_{\mathrm{a}}$ : Area reduction factor. $\mathrm{K}_{\mathrm{c}, \mathrm{e}}$ : Combination factor for external pressures.

$\mathrm{K}_{1}$ : Local pressure factor.

$\mathrm{K}_{\mathrm{p}}$ : Porous cladding reduction factor. $\mathrm{M}_{\mathrm{s}}$ : Shielding multiplier.

$\mathrm{V}_{\mathrm{b}, \mathrm{o}}$ : Fundamental value of the basic wind velocity ( 10 minutes mean wind velocity at $10 \mathrm{~m}$ above ground level open country terrain). $V_{R}$ : Regional 3 seconds gust wind speed.

Table I: Wind code and standard approaches for calculating design wind pressure. 


\begin{tabular}{|c|c|c|c|c|c|c|c|c|}
\hline \multirow{2}{*}{$\begin{array}{c}\text { Building } \\
\#\end{array}$} & \multirow{2}{*}{ Reference } & \multirow{2}{*}{ Scale } & \multicolumn{2}{|c|}{ Building dimensions, m (ft) } & \multirow{2}{*}{ H/B } & \multirow{2}{*}{ Zone width, Z, m (ft) } & \multirow{2}{*}{$\mathrm{Z} / \mathrm{H}$} & \multirow{2}{*}{ Z/B } \\
\hline & & & Height & Width & & & & \\
\hline 1 & Barnaud and Gandemer, 1974 & $1: 75$ & $5(16)$ & $7(23)$ & 0.70 & $1(3.2)$ & 0.20 & 0.14 \\
\hline 2 & Davenport and Surry, 1974 & $1: 500$ & $15(50)$ & $76(250)$ & 0.20 & $5(18)$ & 0.36 & 0.07 \\
\hline 3 & Davenport and Surry, 1974 & $1: 500$ & $15(50)$ & $137(450)$ & 0.11 & $5(18)$ & 0.36 & 0.04 \\
\hline 4 & Davenport and Surry, 1974 & $1: 500$ & $15(50)$ & $152(500)$ & 0.10 & $7(24)$ & 0.48 & 0.05 \\
\hline 5 & Hellers and Lundgren, 1974 & $1: 250$ & $5(18)$ & $12(40)$ & 0.45 & $1(4)$ & 0.22 & 0.10 \\
\hline 6 & Hellers and Lundgren, 1974 & $1: 250$ & $11(35)$ & $12(40)$ & 0.88 & $2(6)$ & 0.17 & 0.15 \\
\hline 7 & Hellers and Lundgren, 1974 & $1: 250$ & $22(72)$ & $12(40)$ & 1.80 & $3(10)$ & 0.14 & 0.25 \\
\hline 8 & Hillier, 1973 & $1: 250$ & $19(62)$ & $44(145)$ & 0.43 & $6(20)$ & 0.32 & 0.14 \\
\hline 9 & Holmes and Best, 1978 & $1: 50$ & $5(16)$ & $7(23)$ & 0.70 & $1(2.5)$ & 0.16 & 0.11 \\
\hline 10 & Jensen and Frank 1965 & Full Scale & $2(5.3)$ & $2(5)$ & 1.06 & $0.4(1.3)$ & 0.25 & 0.26 \\
\hline 11 & Kramer and Gerhardt, 1975 & $1: 250$ & \multicolumn{4}{|c|}{ VARIABLE } & 0.12 to 0.50 & 0.12 \\
\hline 12 & Marshall, 1974 & Full Scale & $2(8)$ & $4(12)$ & 0.67 & $1(2.5)$ & 0.31 & 0.21 \\
\hline 13 & Marshall, 1974 & Full Scale & $5(16)$ & $7(23)$ & 0.70 & $1(3)$ & 0.19 & 0.13 \\
\hline 14 & Stathopoulos, 1975 & $1: 500$ & $15(50)$ & $76(250)$ & 0.20 & $3(10)$ & 0.20 & 0.04 \\
\hline 15 & Stathopoulos, 1975 & $1: 500$ & $69(225)$ & $76(250)$ & 0.90 & $3(10)$ & 0.04 & 0.04 \\
\hline 16 & Stathopoulos, 1979 & $1: 250 / 1: 500$ & $5(16)$ & $24(80)$ & 0.20 & $2(6)$ & 0.37 & 0.07 \\
\hline 17 & Stathopoulos, 1979 & $1: 250 / 1: 500$ & $7(24)$ & $24(80)$ & 0.30 & $2(6)$ & 0.25 & 0.07 \\
\hline 18 & Stathopoulos, 1979 & $1: 250 / 1: 500$ & $10(32)$ & $24(80)$ & 0.40 & $2(6)$ & 0.19 & 0.07 \\
\hline 19 & Surry et al., unpublished & $1: 500$ & $23(74)$ & $50(164)$ & 0.45 & $8(25)$ & 0.34 & 0.15 \\
\hline 20 & Surry et al., unpublished & $1: 500$ & $23(74)$ & $378(1240)$ & 0.06 & $20(67)$ & 0.91 & 0.05 \\
\hline 21 & Surry et al., unpublished & $1: 500$ & $32(105)$ & $132(433)$ & 0.24 & $13(42)$ & 0.40 & 0.10 \\
\hline 22 & Vickery, 1976 & $1: 300$ & $8(25)$ & $30(100)$ & 0.25 & $4(12.5)$ & 0.50 & 0.13 \\
\hline 23 & Vickery, 1976 & $1: 300$ & $15(50)$ & $30(100)$ & 0.50 & $8(25)$ & 0.50 & 0.25 \\
\hline 24 & Vickery, 1976 & $1: 300$ & $20(66)$ & $98(320)$ & 0.21 & $10(33)$ & 0.50 & 0.10 \\
\hline 25 & Wiren, 1971 & $1: 1500$ & $29(95)$ & $61(200)$ & 0.48 & $9(28.5)$ & 0.30 & 0.14 \\
\hline 26 & Wiren, 1971 & $1: 1500$ & $29(95)$ & $122(400)$ & 0.24 & $9(28.5)$ & 0.30 & 0.07 \\
\hline
\end{tabular}

Table 2: Literature sources of experimental studies investigated by Stathopoulos (1979). 


\begin{tabular}{|c|c|c|c|c|c|c|}
\hline \multirow{3}{*}{ Model } & \multicolumn{6}{|c|}{ Dimensions } \\
\hline & \multicolumn{3}{|c|}{ Full scale $(\mathrm{m})$} & \multicolumn{3}{|c|}{ Model Scale $(\mathrm{mm})$} \\
\hline & $\mathrm{H}$ & $\mathrm{L}$ & $W$ & $\mathrm{H}$ & $\mathrm{L}$ & $\mathrm{W}$ \\
\hline $\mathrm{BI}$ & & 60 & 60 & & 150 & 150 \\
\hline B2 & 10 & 120 & 120 & 25 & 300 & 300 \\
\hline B3 & & 180 & 180 & & 450 & 450 \\
\hline B4 & & 60 & 60 & & 150 & 150 \\
\hline B5 & 7.5 & 120 & 120 & 18.8 & 300 & 300 \\
\hline B6 & & 180 & 180 & & 450 & 450 \\
\hline B7 & & 60 & 60 & & 150 & 150 \\
\hline B8 & 5.0 & 120 & 120 & 12.5 & 300 & 300 \\
\hline B9 & & 180 & 180 & & 450 & 450 \\
\hline
\end{tabular}

Table 3: Tested building dimensions. 


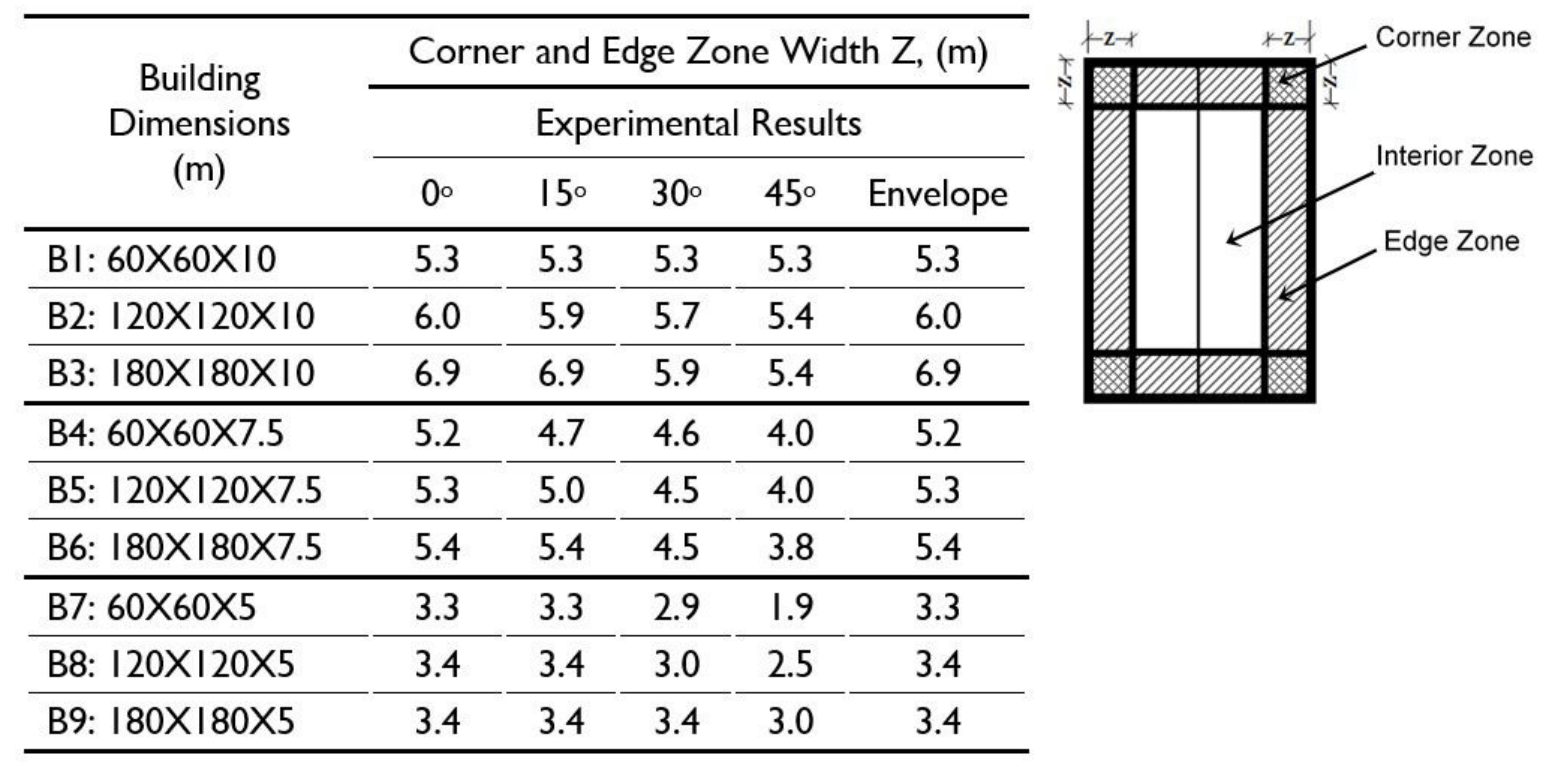

Table 4: Size of corner and edge zone of building models of current study. 


\begin{tabular}{|c|c|c|}
\hline \multirow{2}{*}{$\begin{array}{l}\text { Building Dimensions } \\
\qquad(\mathrm{m})\end{array}$} & \multicolumn{2}{|c|}{ Corner and Edge Zone Width Z, (m) } \\
\hline & $\begin{array}{l}\text { Experimental } \\
\text { Results }\end{array}$ & $\begin{array}{l}\text { Current } \\
\text { Provisions }\end{array}$ \\
\hline $\mathrm{BI}: 60 \times 60 \times 10$ & 5.3 & 4.0 \\
\hline B2: $120 \times 120 \times 10$ & 6.0 & 4.8 \\
\hline B3: $180 \times 180 \times 10$ & 6.9 & 7.2 \\
\hline B4: $60 \times 60 \times 7.5$ & 5.2 & 3.0 \\
\hline B5: I20XI20X7.5 & 5.3 & 4.8 \\
\hline B6: $180 \times 180 \times 7.5$ & 5.4 & 7.2 \\
\hline B7: $60 \times 60 \times 5$ & 3.3 & 2.4 \\
\hline B8: $120 \times 120 \times 5$ & 3.4 & 4.8 \\
\hline B9: $180 \times 180 \times 5$ & 3.4 & 7.2 \\
\hline
\end{tabular}

Table 5: Size of corner/edge zones of current study and the zones provided by ASCE 7-I0 and NBCC 2010. 


\begin{tabular}{lcc}
\hline & \multicolumn{2}{c}{$\begin{array}{c}\text { Value of minimum pressure } \\
\text { coefficient }\end{array}$} \\
\cline { 2 - 3 } $\begin{array}{c}\text { Building Dimensions } \\
(\mathrm{m})\end{array}$ & Edge Zone & Corner Zone \\
\hline B1: 60X60X10 & -2.5 & -2.5 \\
\hline B2: 120X120X10 & -2.3 & -2.0 \\
\hline B3: 180X180X10 & -2.0 & -2.0 \\
\hline B4: 60X60X7.5 & -2.5 & -2.2 \\
\hline B5: 120X120X7.5 & -2.3 & -1.9 \\
\hline B6: 180X180X7.5 & -1.8 & -1.3 \\
\hline B7: 60X60X5 & -2.5 & -2.0 \\
\hline B8: 120X120X5 & -1.5 & -1.5 \\
\hline B9: 180X180X5 & -1.3 & -1.3 \\
\hline
\end{tabular}

Table 6: Minimum values (in absolute sense) of most critical pressure coefficients captured by current ASCE 7-10 and NBCC 2010 roof zones - see Figure 14 for B9, B8, B7. 


\begin{tabular}{lccc}
\hline \multirow{2}{*}{\begin{tabular}{c} 
Building Dimensions $(\mathrm{m})$ \\
\cline { 2 - 4 }
\end{tabular}} & $\begin{array}{c}\text { Corner and Edge Zone Width Z, }(\mathrm{m}) \\
\text { Results }\end{array}$ & $\begin{array}{c}\text { Current } \\
\text { Provisions }\end{array}$ & $\begin{array}{c}\text { Modified } \\
\text { Provisions }\end{array}$ \\
\hline B1: 60X60X10 & 5.3 & 4.0 & 4.0 \\
\hline B2: $120 \times 120 \times 10$ & 6.0 & 4.8 & 4.8 \\
\hline B3: $180 \times 180 \times 10$ & 6.9 & 7.2 & 7.2 \\
\hline B4: $60 \times 60 \times 7.5$ & 5.2 & 3.0 & 3.0 \\
\hline B5: $120 \times 120 \times 7.5$ & 5.3 & 4.8 & 4.8 \\
\hline B6: $180 \times 180 \times 7.5$ & 5.4 & 7.2 & 6.0 \\
\hline B7: $60 \times 60 \times 5$ & 3.3 & 2.4 & 2.4 \\
\hline B8: $120 \times 120 \times 5$ & 3.4 & 4.8 & 4.0 \\
\hline B9: $180 \times 180 \times 5$ & 3.4 & 7.2 & 4.0 \\
\hline
\end{tabular}

Table 7: Size of corner/edge zones of present study and the current zones of ASCE 7-10 and NBCC 2010 compared with the proposed exception. 